
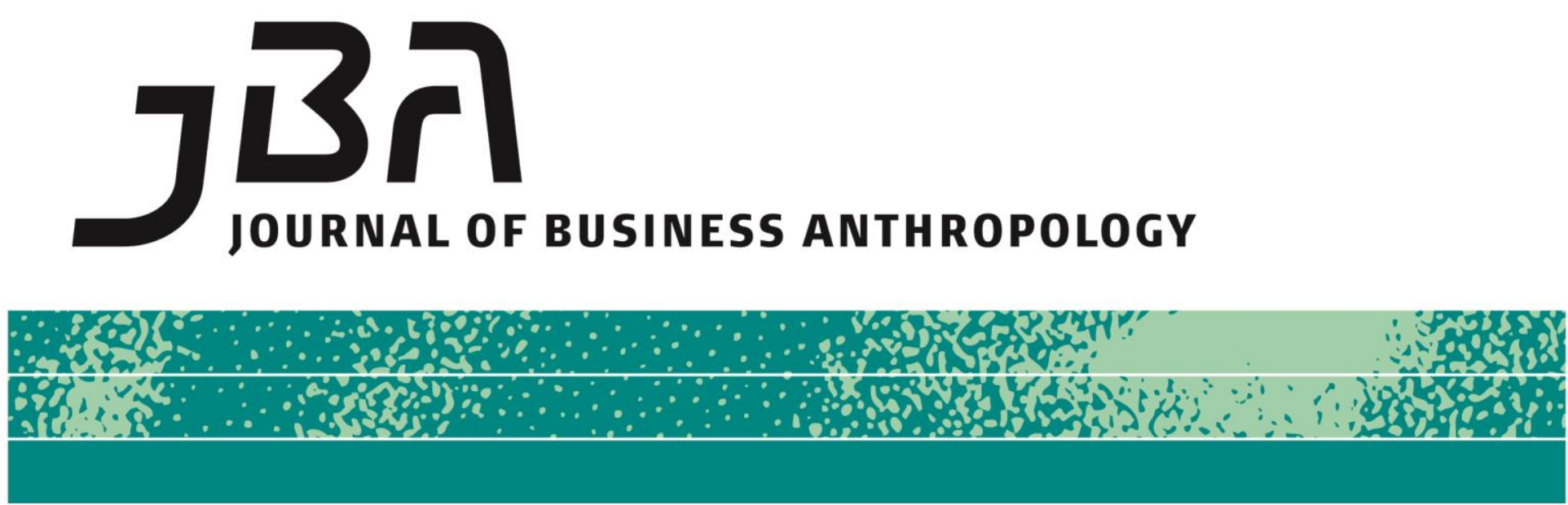

\title{
Opinions: All about Creativity and Innovation
}

\author{
Andy C. Pratt, Doris Ruth Eikhof, Keith Sawyer, Robert D. Austin, \\ Peter Johnson, Martyn Straw, Patrik Wikstrom, Jie Ren, Filip Lau and \\ Mikkel Brok-Kristensen, with an introductory essay by Brian Moeran
}

\section{A Prolegomenon}

Brian Moeran (Copenhagen Business School, Denmark, and the University of Hong Kong)

Several months ago, when Jakob, Timothy and I were planning this spring's issue of the $J B A$, we realised that we would probably have two articles ready for publication on professional people-architects and fashion designers-regarded as "creative." So, in an attempt to overcome the randomness of journal submissions and to create a thematic flow for our readers, we decided to seek opinions on creativity and innovation from people in the business world and from academics who make it their business to conduct research on them. The results are here before you.

Approach more than half a dozen people from different occupational and cultural backgrounds and request them to write about creativity and innovation, and a journal editor looking for textual coherence is asking for trouble! What follows is an eclectic mixture of opinions about the nature of creativity and innovation in virtually all forms of business life: from organizational management to crowdsourcing, from branding to stardom, from workforce neurodiversity to
Page 1 of 70

JBA 4(2): 228-297 Fall 2015

(C) The Author(s) 2015 ISSN 2245-4217

www.cbs.dk/jba 
the various treatments for Toy Story. Written in a variety of styles-some "business-speak," others conversational, yet others academic-these essays offer different people's takes on ideas of creativity and innovation, and support the assertion that, like culture (Williams 1985), creativity is one of the most widely used and misused words in the English language (Negus and Pickering 2004: vi). Neither it nor innovation may be regarded as "a coherent, controlled, well-rounded and clean-edged affair." Rather, both are "dislocated" (Latour 2005: 46)-a dislocation that is most apparent, perhaps, in the intellectual silos in which we all wallow and which, it seems to me, occasionally pushes one or two of us to try to reinvent the wheel. But that, maybe, is what creativity and innovation are all about!

Nevertheless, precisely because of these disciplinary and workplace dislocations, I should admit that I myself learned a lot from these opinion pieces, and that they added to my own understandings of the business of creativity and innovation (Moeran 2014). Like Doris Eikhof, in the past I have on occasion been exasperated by the ways in which people talk about this "mantra." To paraphrase Jana Costas and Gideon Kunda's opinion piece title in the last issue of the JBA: "When I hear the words 'creativity' and 'innovation,' I reach for my gun."

Clearly, there's no "proper" use of creativity or innovation, or of any other word that is, in Andy Pratt's formulation, as deceptive, simple and self-evident, but also elusive (the whole point of "keywords [Parkin 1979, Moeran 1984]). Still, as he then goes on to say, we should be reflexive about our production of knowledge and try to pin things down a bit if we're going to talk about them-something Benoît Godin does superbly in his essay on the shift over time of the word innovation from being forbidden to becoming a cliché, and that Pratt himself does with how $20^{\text {th }}$ century history has affected our understandings and use of both innovation and creativity. Both essays underline the argument that "knowledge is always and necessarily formed in context."

Pratt argues that creativity and innovation are relational activities and that their interaction generates more than the sum of their components. In this respect, a number of scholars (myself included) like to think of creativity and innovation in terms of collaborative engagements, and it is in fact such engagements which underpin the essays that follow here-whether between script writers and film producers, HR managers and autistic employees, or musical stardom and new technologies. They take place on four interlocking levels.

We encounter them, first, among the different agents assigned to a particular project-a gallery director and her employees, curators, artists, and funding bodies (Eikhof); or fashion designers, photographers, models, hair stylists, make-up artists, bookers, advertising clients, and so on and so forth, all involved in putting on a fashion show or shooting an advertising campaign (Mears 2011). 
Engagements also take place between these agents and the institutions by which they are employed (between the "talent pool" and HUGO Boss, for example [Kasper Vangkilde]; or the architects and the firm that is obliged to lay them off in a recession [Aina Landsværk Hagen])-together with their associated hierarchies of power that include both internal positions (creative director, supervisor, trainees, and so on) and external status rankings (Armani, Dolce \& Gabbana, HUGO BOSS, Burberry, and so forth). This is exemplified nicely by Sawyer's account of the zigs and zags involving individual scriptwriters, actors, and organizations such as Pixar, Disney, Hasbro and Mattel (Sawyer). But we also find institutional engagements with individuals (and vice versa) in the enactment of HR and recruitment policies (Rob Austin).

Thirdly, they occur between agents, institutions, and the materials, tools and technologies, together with their associated ideals and budgets, with which they all in their different ways engage and negotiate among themselves-witness Patrik Wikstrom's discussion of the shift from a product-based to access-based music economy; or Jie Ren's account of the development and practices of crowd-sourcing.

And finally, engagements are initiated between all of the above and cultural genres (like the brands discussed by Martyn Straw), in the sense that such engagements "employ conventionalised and specialised occupational practices and practical knowledge, work within an institutional context with its own inherent cultural logic and produce a tangible text, product, or performance" (Dornfeld 1998: 16).

My own take on creativity is that we need to focus on all these different kinds of collaborative engagement, enacted by different participants as they go about conceptualizing, designing, performing or producing, and assessing different organizational forms and cultural goods: on what both Sawyer and Straw refer to as zigging and zagging towards the final goal-whether it be a film treatment or an exercise in branding. These "zigs" and "zags" involve frequent shifts in direction, which themselves drive the creative process forward and lead to one small innovation after another (Sawyer). In this respect, creativity and innovation do not involve thinking "out of the box," as so many people like to think. Rather, as Austin points out, both take place very much "on the edge" of the box (see also Moeran 2014: 3-4). It is on the edge that you encounter neuro-, social, organizational, disciplinary, and product diversity. As a creative director in a Japanese advertising agency once said to me: "With creative ideas you should never be one step ahead of society. If you are, society can't keep up with you. So you should aim to be just a half step ahead."

This raises the question of the extent to which creativity is to be sought in "incremental steps," or in "radical ideas." Sawyer argues for the former; Ren, in the context of entrepreneurial profit and domain-related expertise, for the latter. Different creative activities, it seems, demand 
different approaches; different ways of doing things with different skills engender different levels of results. In the music industry, technological innovations have been disruptive and led to "creative destruction," as online piracy inspired new competitive business models which began to sell music as a service, rather than as products as previously (Wikström). "Positioning," then, is crucial to what Straw refers to as "the win/win" point of differentiation.

\section{Creativity, innovation and improvisation}

Now, it may be that using anthropology by businessmen as a problemsolving tool is "creative and innovative in its own right," as Filip Lau and Mikkel Brok-Kristensen aver, but over the years-perhaps most famously, by Claude Lévi-Strauss (1966)-anthropologists have themselves wrestled with creativity and innovation, and how best to understand and analyse them. John Liep (2001: 2), for example, equates creativity with innovation. This is the way many people think (certainly, the distinction is not entirely clear in some of the essays that follow). But what exactly is "innovation"? Is an innovation necessarily "creative"? And who is going to come up with one: in the case of crowd-sourcing discussed by Ren, are they more likely to be entrepreneurs, people with high expertise, or those with low? Ultimately, we are led to ask: should we equate creativity with innovation, and vice versa?

Two other anthropologists, Timothy Ingold and Elizabeth Hallam (2007: 2-3), would answer in the negative. Contra Liep, they say that creativity and innovation are not the same thing. Creativity, they argue, is forward-looking, whereas one can only gauge when an innovation has taken place by looking backwards at past products (or structures, or social processes). In other words, as Eikhof points out, innovation is utilitarian; it is little other than a means of measurement-something that may appeal to policy advisors, as well as to those writing about innovation management, but of which anthropologists are almost certainly wary.

This raises the question: can creativity be measured? Governments like to think so and cite endless statistical data relating to turnover and employment figures in different forms of cultural production to justify their (often little more than lip service) support for creative industries. But, as Eikhof points out, this support veers towards economic production and "draws attention away from the creative activity itself to the use of its product."

Ingold and Hallam find a way out of this measurement fixation by suggesting that we need to focus on processes of "in-the-making," rather than on the products made-a focus that is at the heart of Sawyer's essay, which seems to suggest that creativity is to be found in process and innovation in the product. At the heart of such forward-looking processes 
is improvisation, which, through small and occasionally surprising changes, may invoke larger implications (see also Sennett 2012: 214). Improvisation is a word that creeps into, and on occasion takes over, some of the opinions that follow-notably Sawyer's account of the development of the treatment for Toy Story. Lau and Brok-Kristensen, for their part, tell the tale of a product brief provided by a gym shoe manufacturer which was quite unable to improvise by thinking beyond its own industry-specific language. Peter Johnson, too, makes a strong call for organizational improvisation as a means towards achieving results in business.

This certainly begins to answer the question, in my own view, of how best to think about and analyse creativity (and innovation). Improvisation is spur of the moment extemporizing. It consists of people "fabricating and inventing novel responses without a pre-scripted plan and without certainty of outcomes; discovering the future that... action creates as it unfolds" (Barrett 1998: 605). In this respect, improvisation is exciting, but also perilous. As Austin notes, it questions the sort of "fitting in" organizations expect. In different forms of cultural production, it obliges people (like Vangkilde's "talent pool" designers) to come up with something whose outcome they cannot necessarily envisage, but which has to be novel and coherent-usually in front of a client or other audience (in the case of these young designers, a HUGO BOSS creative director). Precisely because improvisation takes people away from the security of habitual practice and leads them to "the edge" of the unknown, there is a tendency for them to rely on stock tricks of the trade which have proven effective in the past, rather than to risk failure, even though they know deep down that not to fail is in itself a failure (Barrett 1998: 606-8). Improvisation, then, often comes to be learned, as Johnson argues for organizational improvisation-something that in itself brings to the fore the paradoxical extent to which seemingly unconstrained improvisation is in fact structured.

In this respect, Ingold and Hallam's distinction between backwardlooking innovation and forward-looking improvisation seems at first glance neat. Alas! It doesn't quite work in practice. It is often hard for those working together in collaborative situations to detach improvisation from innovation, process from product. Perhaps this is a characteristic particular to cultural production in the "creative" industries, which are always conceptualising and manufacturing new products on the basis of past products and experiences. For them, primarily because they are working for the most part with defined genres and brands, the present is the past (something that Straw, for example, in his discussion of branding, would probably like to get away from). As a result, we end up saying that creativity is product-as-process, neither one, nor the other, but both together. As Sawyer (2006: 157) has pointed out elsewhere, "improvisation couldn't take place at all without some shared conventions, because otherwise communication would be impossible." 
This suggests that creativity is rarely a Great Leap Forward, but rather consists of a series of small steps akin to the pigeon-toed shuffle of a geisha.

\section{Thinking aside}

So what more do we need to explain creativity? Creative products in themselves are characterised by what Howard Becker (2006: 24) has called a "fundamental indeterminacy." Films, fashion shows, studio shoots, and music gigs vary enormously, even though they may be realised by the same personnel in, to all intents and purposes, the same environments using the same materials and techniques. Yet they are all marked by a series of choices by participants: those zigs and zags so nicely described in Sawyer's account of the conceptualization of Toy Story. It is the "combination of routine and unusual choices among available possibilities" (Becker 2006: 25-6) that gives every creative product its character.

What affords such choices, therefore-materials and available technologies, aesthetic ideals, genre and cultural style, personal networks, power relations, money-should be our main concern (Moeran 2014: 3559). We see this combination of affordances at work in Wikström's essay on how technological changes in the music business are accelerating access-based music services, which themselves are beginning to reduce "the value and significance of artist-based music brands." Similarly, crowdsourcing has only become possible through the development of online platforms (Ren). The concept of affordance would, I think, also help firms and other organizations when they decide to innovate. It is certainly what has enabled the JBA to publish the "speed video" by Simon Lex Westergaard and his students.

It has already been suggested that creativity involves moving to the edge of the box. Let me take this suggestion a little further. To be able to move to the edge, you have, necessarily, to be able to "think aside" (Koestler 1970: 144-77)-something argued strongly for in Straw's discussion of brands. This is no easy task. As any Zen novice will aver, the harder you try to find the answer to what the sound of one hand clapping might be, the less likely you are to find it. And yet you have to try and try again, because it is when you are beating your head against the wall of the box in frustration that, quite suddenly, a totally unexpected answer is likely to come to mind. Creativity, then, involves thinking aside, and thinking aside demands discipline, skill, hard work and patience.

Creativity is based on graft, and not on an inexplicable gift from the Gods.

Thinking aside is characteristic, as Koestler argues, of humour, science, and art. Each sees analogies which nobody has seen before-whether in a pithy saying ("Statistics are like a bikini. What they reveal is suggestive. What they conceal is vital"), discovery (Kepler's 
linking of the physical and metaphysical in gravity and the Holy Ghost), or visual image (Meret Oppenheim's Cup, saucer and spoon in fur). While people working in different forms of cultural production may not aspire to such Eureka acts, they do, nevertheless, attempt to uncover things that have always been there but "hidden from the eye by the blinkers of habit" (Koestler 1970: 108). They bring together hitherto separate planes of experience in order to afford "originality," which often-like metaphor-consists of no more than a displacement of attention to something that was irrelevant before, but is now made relevant (ibid. p. 119).

The aim, then, is to free the mind of those constraints which are necessary for it to maintain a disciplined routine in everyday life, but which at the same time prevent the "blindingly obvious" from emerging. In Koestler's words again:

Ordered, disciplined thought is a skill governed by set rules of the game, some of which are explicitly stated, others implied and hidden in the code. The creative act, in so far as it depends on unconscious resources, presupposes a relaxing of the controls and a regression to the rules of verbal logic, unperturbed by contradiction, untouched by the dogmas and taboos of so-called common sense. At the decisive stage of discovery the codes of disciplined reasoning are suspended-as they are in the dream, the reverie, the manic flight of thought, when the stream of ideation is free to drift, by its own emotional gravity, as it were, in an apparently "lawless" fashion (ibid. p. 178).

\section{References}

Barrett, F. 1998 "Coda: creativity and improvisation in jazz and organizations: implications for organizational learning." Organization Science 9 (5): 605-22.

Becker, H.S. "The work itself." In H. S. Becker, R. R. Faulkner and B. Kirshenblatt-Gimblett (Eds.) Art from Start to Finish. Chicago and London: University of Chicago Press.

Dornfeld, B. 1998 Producing Public Television, Producing Public Culture. Princeton, NJ: Princeton University Press.

Ingold, T. and E. Hallam 2007 "Creativity and cultural improvisation." In their edited Creativity and Cultural Improvisation. Oxford: Berg.

Koestler, A. 1970 The Act of Creation. London: Pan.

Lévi-Strauss, C. 1966 The Savage Mind. London: Weidenfeld \& Nicolson.

Liep, J. 2001 “Introduction.” In his edited Locating Cultural Creativity. London: Pluto.

Mears, A. 2011 Pricing Beauty: The making of a fashion model. Berkeley \& 
Los Angeles: University of California Press.

Moeran, B. 1984 "Individual, group and seishin: Japan's internal cultural debate." Man 19 (2): 252-66.

Moeran, B. 2014 The Business of (Creativity: Toward an anthropology of worth. Walnut Creek: Left Coast Press.

Negus, K. and M. Pickering 2004 Creativity, Communication and Cultural Value. London: Sage.

Parkin, D. 1979 The Cultural Definition of Political Response. London: Academic Press.

Sawyer, R. K. 2006 "Group creativity: musical performance and collaboration." Psychology of Music 34 (2): 148-65.

Sennett, R. 2012 Together. London: Allen Lane.

Williams, R. 1985 Keywords. (Revised Edition.) Oxford: Oxford University Press.

\section{Do Economists Make Innovation; Do Artists Make Creativity? The Case for an Alternative Perspective on Innovation and Creativity}

Andy C Pratt (City University, London)

The contemporary imperative is to use knowledge, and to apply it to innovation, and in turn to boost the scale and scope of economic production. We are bombarded with "knowledge," the need to gain it, or deploy it effectively. However, we seldom pause to differentiate between good and bad knowledge; all knowledge seems to be equal and positive. Thus, this is not knowledge (or even information) overload (implying the need to sift and filter it), but knowledge as universal object: knowledge management, knowledge exchange, knowledge transfer, and the knowledge economy.

Such use of language simultaneously points to, but then obscures, its object. It is a process that sociologists of knowledge refer to as "black boxing," a rhetoric that reduces the "knowledge problem" to one of logistics and organisation: the nature of knowledge is "bracketed out" (Pratt 1998, Pratt 1997). It is striking that neo-classical economic discourse characterises knowledge as an externality; that is, it is something not an intrinsic part to the economic problem. This essay seeks to place the knowledge question at the centre of our analyses, and subsequently suggests a radical re-interpretation of innovation and 
creativity. I will argue that there is, furthermore, an important specificity to knowledge "in action," which I illustrate by reference to the cultural economy.

My aim is to provoke, and to provide a different lens-one that challenges the view that regulation and organisations simply "get in the way" of the free circulation of knowledge. In short, I wish to confront the formulation of the problem, normally stated, characterised as guaranteeing the supply and distribution of knowledge: as the multiplication of management paper and textbooks on the topic will testify. A parallel trend has been to recognise that the field of arts and culture does not seem to face the same problem. In the field of arts and culture-the creative industries-all the latter do is produce "newness": creativity and innovation are in abundance (Pratt and Jeffcutt 2009). Moreover, the "creative turn" in management has acknowledged that artists and cultural activities are quite good at both producing and managing knowledge under complex and risky situations; suggesting that what they do with knowledge might be important.

It is a commonly held view that "new" knowledge, manifest in novel goods and processes, is what drives the economy and society. Simply having knowledge is not sufficient; it has to be used, or applied to a specific problem. This is why we have the "problem" of knowledge transfer and exchange. It is commonly stated that the contemporary economy is/will be a knowledge economy, and thus the imperative to produce more knowledge. It is not the economy of knowledge, as economic norms might express it (and how to fix market imperfections); rather it is knowledge itself that is constitutive of the economy and its dynamics. Accordingly, in this essay I will reverse the normative argumentative order, and consider the challenge of "knowing" knowledge. I will reject the universal and atomised view of knowledge: what counts as knowledge in one time/place is different to another.

This organisational twist to economic action is an anathema to normative economists, who see organisations and institutions, as well as knowledge, as external factors, which can be assigned a residual value in an equation. More shocking still, for those economists who have wandered outside the iron cage of their normative discipline, have been relational or post-structural critiques of economics. In a series of intriguing and provocative studies economics has been deconstructed, and the disciplinary logic exposed. A particularly challenging text argues what is a heresy for economists: that economists make markets (in other words, the latter are not "natural," but a construct; moreover that they encourage us to act as if the market existed: people and markets are wrong, not economic theory)(MacKenzie, Muniesa, and Siu 2007). In this essay I follow this lead and pose the questions: do economists make innovation; and do artists make creativity? I will argue that the discursive formation of innovation and creativity effectively blinds us to the social 
actions of knowledge creation (that is, humans acting, not humans \{economists\} writing about doing). Moreover, that it would be productive to take a new look at the process of what we term "innovation and creativity" without bracketing out knowledge. Instead of treating them as exceptional and rare, I argue that we should see non-creativity and noninnovation as exceptional, and an achievement; just as much as maintaining creativity and innovation are an achievement.

\section{Innovation and creativity}

Innovation and creativity are deceptive terms: simple and self-evident, but also elusive. It is this dualistic and functionalist character that makes them such tricky topics for social scientists and policy makers. Debates about innovation and creativity have generally generated more heat than light concerning our understanding of the phenomena in question. This black boxing hides three topes: the first is idealism and universalism: these terms are deployed as if they were universal in time and space. Second, innovation and creativity are presented as a "missing link" that needs fixing, disclosing a functionalist conception. Third, creativity and innovation are presented as normative for economic production: they are considered to apply to all sectors of the economy equally. The "economy" in question is one based on manufacturing techniques and the addition of science.

My line of argument will challenge normative perspectives. However, I am not assuming that I can simply suspend all preconceptions, rather that we should be reflexive about our own production of knowledge. Specifically, to understand how it is embedded in role and norms, and disciplinary structures. This speaks to the role of science and the legitimation of knowledge and truth as a reflexive act. This is a rather over-ambitious agenda, but it is indicative of the ground clearing that we need to do before attending to an analysis of innovation, particularly that in the cultural economy (see below).

In terms of economic history the significance and form of innovation and creativity is variable. It is notable that in developed economies creativity and innovation are perceived to be in crisis now, and for the last century. Arguably, this is not due to a lack of knowledge, but rather the function that innovation has been required to perform in relation to the dominant forms of economic activity: mass production. The Fordist form of mass production and consumption, and its regulation, stabilised on the basis of the scale of production. Innovation, in terms of quantity was needed; but less attention was paid to economics of scope beyond pressing the margins of market share. Science and technological knowledge was institutionalised and regulated in a similar fashion, from schooling to the laboratory. Emblematic was the battle of US car manufacturers with extreme styling of cars (such as tailfins and streamlining) which promoted the continual deployment of fashion and 
design elements to drive product turnover and serial and multiple purchases.

The crisis came with under-consumption triggered by the oil crisis of the 1970s. Process innovation was important in the development of post-Fordism and flexible specialisation, which was a way of reconfiguring markets to economies of scope and once again generated a demand for new products, especially those that differentiated by design characteristics. Arguably, the "need" for product innovation to satisfy the scope economies that were driving markets generated "a crisis of innovation." The post-Fordist model was based on hollowing out the large production unit, outsourcing activities and risks: research and development were one such area in many companies. Rather than being inside the corporation, innovation was outsourced to the network. Indeed academic knowledge "discovered" this in the notion of "open innovation." In the same way, the development of science parks was promoted to enable technology transfer between universities and companies. These were different ways of filling an innovation "hole" generated both by the hollowing out of companies, and the need for scope economies.

What about creativity? On one hand, it can be appreciated that the increasingly fast fashion cycle of products, and the demand for more "new" products provide one dimension of the demand for creative output. This is an argument for the increasingly industrialisation of cultural production that has been intensified from the early $20^{\text {th }}$ century onward. On the other hand, we can see the internal problem of art, which is the value system that does not correspond to the economic value system. The artistic value system is complex, but has commonly been reduced, as with science, to the genius who generates unique and distinctive discovery which as a result of its unique qualities transforms the world (Pratt 2008). This tension has constituted the conditions of the birth and consequent form of the cultural economy in the $20^{\text {th }}$ century. The following section points out the particularity of the cultural economy, and why the atomised and universal "genius" offers a poor understanding for the interaction.

\section{Cultural economy}

The labels used capture the twists and turns of the debate from the original usage of "culture industry" as an opposite to culture in the Frankfurt School usage; to the cultural industries notions of French communications theorists; to the nominalist creative industries of the British government, and the associated "creative class" and "creative city" deployed by Richard Florida to denote a current modality of place marketing and consumption politics. Finally to the "creative economy" of UN agencies, which has morphed into the "cultural economy'(Pratt 2009, in press, Pratt 2011). 
This is not the place to deconstruct the labels and the conceptualisations that are deployed in the "cultural economy." Suffice to say that it is a contested area: there are three strands. First, one that has progressed from a focus on the interrogation of the symbolic value of culture and cultural consumption, then cultural production (as opposed to cultural consumption), and finally to a wider conceptual field of a cultural eco-system. Second, analyses that have used the relationship to markets as differentiator: state versus market, for-profit versus not-forprofit, formal activities versus informal activities. Third, those that have used predefined categories to legislate "creative" from "non-creative" activities, or "cultural" from "non-cultural" ones.

These debates are serious and complex; however, my purpose here is to highlight the problematic use of the modifier "creative" as if it were a simple matter to identify a "creative" act or product, outside of its context. Moreover, I want to highlight the tension between the words "culture" and "economy." Thus my point here is to point out that the cultural economy signifies a contested field, critically one that draws upon non-normative disciplinary assumptions.

An illustration of this point is that the "cultural turn" in the social sciences has re-discovered the "cultural dimensions" of everything, and that they may be susceptible to cultural analysis. Thus we have had many interesting accounts of the "cultural economy." Despite the apparent unorthodox position, such accounts have failed us. First, they have sought to look at the cultural dimensions of the economy, yet empirically they failed to examine the cultural industries (which one might have expected to be the genuine "hard case"). Second, the work is normative. Normative in the sense that it re-produces the Parsonian divide between economics and sociology that informed the realm of economic sociology, and economics from the second half of the twentieth century onwards (Pratt 2004). Framing all attempts to challenge the formulation as dualistic, such a division is essential for the disciplinary constitution of contemporary economics; basically economic sociology is an "externality," or a "residual."

Thus, any rigorous analysis of the cultural economy faces a number of challenges based, first, in various ways, on taxonomy: that is on what or which is the object of analysis; and second, on the mode and logic of analysis. The two are of course related: ontology and epistemology. Here a meta-anthropology of academic analyses is necessary: why do these different tribes decide on particular taxonomies of the world? Nominalist-empiricist and positivist economics simply groups "similar things" together (however, this breaks down in such a nominalist world view: all red things, or flat things, etc.?). In this case the "similar" is a natural order of manufacture and with it a material's physical transformation. When we begin to consider the "service industries" or "knowledge economy," let alone the "virtual economy," 
such a classification breaks down.

Interestingly, this does expose the epistemological flank of the debate: how do things happen? Empirical tracking of correlations can offer implied causation; a process that can appear reliable manipulating physical objects. However, attributing causes of particular effects in a virtual or symbolic sense consists at best of guesses. Causal analysis requires a more materialist argumentative strategy, and in so doing draws in a wider, or different, set of objects which processes relate together to generate cause.

Thus the philosophically materialist line of argument constructs the cultural economy using the set of activities and materials that are necessary to make a "cultural product" exist. That is, for contemporary popular music to exist, as Patrik Wikström shows in his essay here, we have to pre-suppose recording, distribution and playback technologies and platforms, as well as regulatory structures such as intellectual property rights, a meaning system associated with music and its symbolic value, and its dissemination. We also need to consider the formation of music performance and composition skills, and their formation.

\section{“Culturalised" knowledge}

The line of argumentation in this essay has been to decentre knowledge, and to situate it, or embed it, in social and spatial processes: to propose a relational definition of knowledge. As I argued at this beginning of this essay, a central problem has been the "bracketing" of knowledge in debates about innovation and creativity-a point of view that resists a relational perspective. We have noted how such a perspective might be relevant in accounts of economic change, and in explaining the particularity of the cultural economy. In this section I want to draw upon some threads of philosophical and sociological rationales for such an argument.

The philosophy of science has concerned itself with the logical arguments for causation (epistemology), and with the nature of things (ontology). Contemporary science, and debates about the nature of innovation, are founded on logical positivism: a nominalist and atomistic argumentative framework. As cause cannot be directly sensed, it must be inferred; it can only be verified under particular conditions, typically those of the laboratory. The normal account of science is based upon removing interference in the reaction under investigation. Critics of logical positivism have argued that the notions of ontology (nominalism), and the assumption of radical randomness of events are incorrect premises. In essence, this is a philosophical stand-off, as both accounts can be logically sustained (Bhaskar 1989, 1975).

Sociologists of scientific knowledge have been able to offer a radical "test" by taking essentially an anthropological approach to 
scientific practice. They have begun by observing scientists and forming a conception of the world that their actions assume (Woolgar 1988, Latour and Woolgar 1986). In simple terms, the messy laboratory is rendered into neat science when it is written up. Logical positivism is retroactively "proven." Sociologists of scientific knowledge have sought to understand what scientists actually do, as practices. Their conclusions are that these practices are not accounted for by logical positivism, but by a relational understanding-where a correspondence, not absolute, truth is the norm. Moreover, in order for laboratory experiments to "succeed" in the outside world, the world itself has to be changed (Latour 1988, 1987). This does not undermine the fact that new practices and reactions are achieved, but it questions both the reason for them, and the (non-) independence of knowledge. Knowledge is always and necessarily formed in context. This conclusion has a radical impact on the models and conceptions of innovation and creativity that lie at the core of economic and management science.

The associated epistemological debates are anti-foundational ones, and can be followed via the contemporary critique of economic sociology, and sotto voce, a critique of economic anthropology. The pivot point in this literature is the exploration of a relational social science: of how meanings are co-constructed in debate and practice. David Stark's (2009) inspiring account of some of the boundaries of social analyses of economic action and of value offer a provocative way forward. This work shares a common foundation of a relational social science: Actor-

Network-Theory. ANT develops a radical ethnographic approach to meaning making, objects, and their relationships; it positions itself as a non-human-centric account of the world (in that it seeks "non-humans" as potential actants embroiled in a network).

The pioneering work by Callon (Callon, Millo, and Muniesa 2007, Callon 1998) and colleagues, in particular, has turned attention to the interrogation of economic action: exemplars being ethnographic studies of markets and pricing. A radical extension of work-notably by MacKenzie (MacKenzie 2009) and Knor-Certina (Knorr-Cetina and Preda 2006)-exploring that most obscure field of financial modelling in hedge funds. Allied to this is the thesis that economic theories make markets, rather than theories accounting for, and explicating markets. Inspiring though this is, it is notable that few attempts have been made to turn such an analytical lens onto the cultural economy. This is the subject of the final section.

\section{Discussion}

This essay has sought to interrogate and re-configure the question of innovation and creativity. I have taken the reader through a number of ways in which knowledge has been obscured by, and excluded from, an analysis for which it is allegedly the subject. Analyses of knowledge have 
assumed that it is a "thing" that is amenable to transaction and exchange, independent of its value, or its constitution. This view, I have argued, is but a construct of economic theory. I have shown that there is a body of work that would challenge such a normative view, offering a relational and social constructivist alternative. This is an argument that is rooted in the philosophy of science and the study of technology, and has been extended (controversially) to the field of economics and sociology.

This argument is disruptive of notions of innovation, cause and effect; and of the (lack of) social dimension of scientific and economic processes. Finally, we can point to the fact that the cultural economy is ripe for the application of these insights. The false dualisms of economic and cultural value (that is, the values imposed upon the field) disintegrate in complex forms in the light of closely and attentively observed cultural practices.

The normative view of the cultural economy is that it is in some way a deficient, or poorly disciplined version of the economy. The suggestion from this paper is that we might instead consider the cultural economy as a more "normal" state of affairs, and the abstracted "economy" the exception (if at all). The socially and culturally embedded forms of social action that constitute "markets" are important, and constitutive: they are not residuals. Innovation and creativity are relational activities; they are based upon social interaction and ideas. They have a generative relation, thus the interaction can be more than the sum of its components. In fact, it would be a fair characterisation that this interaction in situ is generative of ideas; but such ideas and practices have to be recognised for what they are (so the same ideas might not be understood by others, with different histories and imaginations). Moreover, further interactions, under different conditions are required before a potential "application" (anticipated or unanticipated) is found. Even then, the application may not be acknowledged or accepted by a social group or organisation, and it may be forgotten. There is no necessity for ideas and inventions simply to become apparent.

In what may seem like a rather dilated argument, I have argued that many normative notions of innovation and creativity could be usefully "turned on their heads," or have their logical order reversed. Moreover, the dominant characterisation of innovation, invention and creation is atomistic, and should be cast aside in favour of a relational understanding. In so doing we might perhaps approach an understanding of the cultural economy-not as a failed, inefficient, or ineffective economy, but as a more useful "model" of action. Perhaps, then, we will avoid the conceit that economists make markets, and artists make creativity. The application of a humble anthropological perspective might help us to take more seriously what actually happens, as opposed to what we'd like to, or what should, happen. The study of innovation and creativity is, I would argue, at the very beginning of a new journey. A good 
place to begin is with the cultural economy.

\section{References}

Bhaskar, Roy. 1975. A realist theory of science. Leeds: Books.

Bhaskar, Roy. 1989. The possibility of naturalism : a philosophical critique of the contemporary human sciences. 2nd ed. ed. New York ; London: Harvester Wheatsheaf.

Callon, Michel, ed. 1998. The laws of the markets, Sociological review monograph series. Oxford ; Malden, MA: Blackwell Publishers/Sociological Review.

Callon, Michel, Yuval Millo, and Fabian Muniesa. 2007. Market devices, Sociological review monograph. Malden, MA ; Oxford: Blackwell.

Knorr-Cetina, K., and Alex Preda. 2006. The sociology of financial markets. Oxford ; New York: Oxford University Press.

Latour, Bruno. 1987. Science in action : how to follow scientists and engineers through society. Milton Keynes: Open University Press.

Latour, Bruno. 1988. The Pasteurization of France. Harvard: Harvard University Press.

Latour, Bruno, and Steve Woolgar. 1986. Laboratory life : the construction of scientific facts. Princeton, N.J: Princeton University Press.

MacKenzie, Donald A. 2009. Material markets : how economic agents are constructed. Oxford: Oxford University Press.

MacKenzie, Donald A., Fabian Muniesa, and Lucia Siu. 2007. Do economists make markets? : on the performativity of economics. Princeton, N.J.: Princeton University Press.

Pratt, A. C. 1997. "The emerging shape and form of innovation networks and institutions." In Innovation, networks and learning regions, edited by J. Simmie, 124-136. London: Jessica Kingsley.

Pratt, A. C. 2004. "Retail Therapy." Geoforum 35 (5):519-521.

Pratt, A. C. 2008. "Innovation and creativity." In The Sage Companion to the City, edited by John R. Short, Phil Hubbard and Tim Hall, 266-297. London: Sage.

Pratt, A. C. 2011. "An economic geography of the cultural industries." In The Sage handbook of Economic Geography, edited by A. Leyshon, L. McDowell and R Lee, 323-338. London: Sage.

Pratt, A.C. 1998. "Science, technologie, innovation: ouvrir la boite noire." In Recherche et développement: travaux Franco-Brittaniques. , edited by J Cohen, D Hart and J Simmie. Paris: Publications de la Sorbonne. 
Pratt, A.C. 2009. "Cultural economy." In International Encyclopedia of Human Geography, Volume 2, edited by R Kitchen and N. Thrift, 407-410. Oxford: Elsevier.

Pratt, A.C. in press. Cultural economy. In The International Encyclopedia of Geography: People, the Earth, Environment, and Technology, edited by D Richardson. New York: Wiley.

Pratt, A.C., and P. Jeffcutt, eds. 2009. Creativity, innovation and the cultural economy. London: Routledge.

Stark, David. 2009. The sense of dissonance : accounts of worth in economic life. Princeton, N.J. ; Woodstock: Princeton University Press.

Woolgar, Steve. 1988. Science : the very idea, Key ideas. London ; New York: Routledge.

\section{Creativity and Innovation: Or, What Have the Arts Ever Done for Us?}

Doris Ruth Eikhof (University of Leicester, School of Management)

My typical reaction to the words "creativity" and "innovation" in close proximity is exasperation mixed with pessimism. Like probably no other phrase, creativity and innovation stand for a "creative industries-turn" in cultural policy that occurred from the late 1990s onwards (Menger 2013, Oakley 2009, Oakley et al. 2014). In the UK, the complementing visual of this creative industries-turn was the image of Oasis guitarist Noel Gallagher attending the then newly elected Prime Minister Tony Blair's media party at 10 Downing Street in 1997: a new era with arts and culture at the heart of policy. Nearly two decades and much critical discussion later, the "creativity and innovation" mantra seems to have lost none of its power and promise. As a researcher of cultural work I "naturally" get asked to write about creativity and innovation, or to apply for research money from innovation-focused funding schemes. I say arts and culture; you say creativity and innovation. My heart sinks every single time. And here is why.

Just before the millennium, Tony Blair's New Labour government in the UK set up a Creative Industries Task Force, whose seminal mapping document defined the creative industries as a key target of public policy (Hesmondhalgh and Pratt 2005, see Menger 2013 for European cultural/creative industries policy more broadly). At the heart of this policy shift was the belief that those industries that "have their origin in individual creativity, skill and talent" (DCMS, 2001: 5) make two socio- 
economic contributions. Firstly, they turn creativity into marketable innovations, thereby generating economic growth and high skill/high wage employment (e.g. Clifton et al. 2009, Chapain et al. 2010). Secondly, they attract the so-called creative class (read: educated, high spending, tolerant and community-oriented people) which helps transform tired urbanities into diverse, multi-cultural breeding grounds for sustainable livelihoods and makes them attractive for investors (Florida 2004). Consequently, money was made available to develop creative clusters, business incubators and re-branding initiatives (Landry 2000). Berlin's "poor but sexy" campaign is a poignant example of a whole metropolis successfully trading on the image of the authentically impoverished creative to attract global investment (Neate 2014). In Britain, pretty much every small town now has its share of creativity-branded small business spaces flanked by independent coffee shops.

What at first glance might have looked like welcome attention for the arts and culture soon turned out to be a take-over of cultural policy by economic policy in search of a palatable-even hip or cool-attempt at economic and social engineering (Oakley 2004, Peck 2005). The visually most notable consequence of creative industries policy has been accelerated gentrification. The less well-off have been priced out of facelifted neighbourhoods in which the creative class now sips fair-trade flat whites and craft beers, "burnt-out beautiful people" (Rainnie 2005: 9) recovering from their daily slog of advancing the knowledge economy. The creative class' urbanities do not house a new society with "full opportunity and unfettered social mobility for all" (Florida 2004: 321), but merely provide an anti-bourgeois, anti-corporatist ambience that helps educated workers reconcile their humanist career ambitions with the realities of a capitalist system that remains money-focused, under contemporary austerity more than ever.

There is also considerable debate over whether the creative industries have delivered and can ever deliver on the first set of expectations, those concerning their more direct contributions to the economy: that is to say, GDP growth or high skill/high wage employment (e.g. Comunian 2009, Warhurst 2010). Reviewing pre-financial crisis data, Comunian (2009) shows ambiguous evidence of which of the newly labelled creative industries deliver employment and GDP growth. New jobs mainly seem to be opening up in IT-related industries, rather than in traditional arts and culture organisations or in SME craft production. IT giants such as Google or Facebook may look like creative new worlds of work (Walker 2013), but whether their informal working cultures are the source of their product market success, or a perk they can afford because of it, remains open to debate. Once the internet economy's supporting infrastructure is factored in, the picture certainly turns much darker, with market leaders such as Amazon providing innovation based on exploitative working cultures and low wage/low skill jobs (Kantor and Streitfeld 2015). 
This ambiguous evidence of the benefits of creative industries policy is why the "creativity and innovation" mantra exasperates me, especially in its glossy policy report guise. For the umpteenth time: it does not work that easily; the creative industries do not immediately deliver a stylish, diverse brave new world for all, and no number of new creative clusters is going to change that. Fortunately, my exasperation may well have a short(ish) shelf life. After nearly two decades, the next policy paradigm du jour can't be far away (hipsters and the sharing economy, anyone?). Surely the band waggons will move on and leave the arts and culture to breathe freely once again.

I say arts and culture, you say you're busy elsewhere. Unfortunately, it is at this point that pessimism creeps in. Creative industries policy looks to me to have changed arts and culture substantively and in ways that may well undermine their vitality and sustainability long after the policy band waggons will have disappeared over the next silver lined horizon. My concerns arise from observations of practices of cultural production over the last decade. I will briefly sketch the underlying concepts before turning to two illustrative cases from my research in the UK .

In his 1983 article, "The field of cultural production," Pierre Bourdieu outlines how cultural production essentially comprises three main practices: artistic practice, position-taking, and economic engagement. As artistic practice Bourdieu understands instances of original creation that are driven by artistic or creative motivations-for example, the production of a play, or the curating of an exhibition. Practices of position-taking aim to place individuals or organisations within the cultural sector-by establishing reputation in a particular genre, for instance, or by collaborating with certain artist or organisations. Economic engagement comprises practices focused on markets within and outside the cultural sector: for example, selling/exhibiting cultural outputs, securing financial capital, or recruiting artists.

The field's raison d'etre lies in its artistic practice, in which individuals follow an intrinsic drive to create and express and find themselves in a flow-like state where "ordinary human capacities are transcended to produce excellence beyond convention" (Banks 2014: 242). Position-taking and economic engagement are undeniably essential for cultural production: position-taking makes artistic practice recognisable as such, and positions it for assessment-by its artistic genre, for instance, or by its quality; economic engagement secures financial, and coordinates human, resources. In themselves, however, neither positiontaking nor economic engagement produces art, culture or creative activity. They do not constitute, in the language of economic production, the core business of the sector. It is artistic or creative practice in its various guises, especially when experienced as a "perfect synthesis between the 
worker and the work" (Banks 2014: 242), that marks cultural production as a field and attracts and retains cultural workers (Eikhof and York 2016).

However, a marked disjuncture is becoming apparent between, on the one hand, the importance that cultural workers attribute to artistic practice and, on the other hand, the space given to artistic practice in cultural production; cultural workers' ability to present and advocate for it; and the influence it is allowed on other practice, in particular economic engagement. I recently analysed documents with which cultural organisations had applied for funding. In those documents, the applying organisations competently outlined their contribution to the economy and local communities: in other words, the wider benefits of their cultural production. When questioned about their artistic practice, answers were markedly more general, hollower and much shorter. Asked to list their strengths, the majority of organisations forgot to mention anything relating to art or culture at all, typically listing the efficient use of resources or community contributions instead. Indicatively, only a very small share of the funder's questions actually required the organisations to talk about their artistic practice, or their core business, itself. The vast majority of the documents concerned either the organisation's position within its respective field or, overwhelmingly, practices of economic engagement-typically an organization's contributions to communities, or what role it saw itself playing within the cultural economy. In short: artistic practice was barely part of the conversation and, where it was, the cultural organisations themselves were remarkably poor at talking about and making a case for it.

The gist of these sector-level conversations I saw mirrored at the micro-level of cultural production. An indicative example was that of a gallery, small in numbers of staff but a medium to large player in its field in terms of reputation and positioning, which had contacted me to help it develop new ways of attracting income. Reviewing the gallery's activities, it emerged that a preoccupation with practices of economic engagement, in particular funding applications and developing new business opportunities, had to a substantial extent crowded out artistic practice. Gallery staff were still motivated by artistic practice as such, and described discussions about art works, artists, techniques and curating as their reason for getting out of bed in the morning. However, many of these discussions were no longer taking place in the gallery itself. In the most illustrative case they had physically relocated to the kitchen table of a flat shared by two key staff. One of the two flatmates described how they would while time away in meetings with gallery colleagues, while discussing art at home for hours on end without giving the clock so much as a glance. Similarly, the gallery's director had gone part-time to engage in freelance curating and artistic work-the same type of work she was contracted to do for the gallery but could not make enough time and creative headspace for, given the position-taking and economic 
engagement practices her director's position increasingly required.

Once in the gallery, most conversations and activities focused on where money might come from, which income streams could best be developed and how existing activities could be organised more efficiently. Similar to the funding applications described earlier, the conversations within the gallery were replete with eloquent articulations of its contributions to communities, the city and the cultural sector more broadly. But, while staff recognised these discussions as necessary, they also described them as wearying, soul destroying or, at best, simply boring. The increasing prevalence of economic engagement zapped staff motivation to work in and for the gallery-in particular, to work overtime or put in additional effort. The artistic practices undertaken offsite, on the contrary, were what fed their desires and energy for working in cultural production. It became clear that reclaiming a more prominent and protected position for artistic practice in the gallery was even more important for the gallery's sustainability than developing new funding and business opportunities.

These two examples are illustrative of how artistic practice can be "crowded out" (Eikhof and Haunschild 2007) of its central position in cultural production while position-taking, and especially economic engagement, take up an increasing amount of space, or even start to dominate. In particular, the problematic situation the gallery found itself in evidenced how dangerous such crowding out of artistic practice can be. When economic engagement grows, cultural production loses its raison d'etre; it loses that which constitutes it as a field in itself and for itself. Crucially, it also loses its vital distinction from the economic field, the essence that allows Bourdieu (1983) to describe arts and culture as an "economic world reversed." In short, imbalances between artistic practice, position-taking, and economic engagement endanger the vitality and sustainability of cultural production.

From my observations, creative industries policy-with its buzzwords, "creativity" and "innovation"-facilitates such dangerous imbalances. Firstly, by focusing on creativity rather than on art or culture, creative industries policy broadens the scope from that of traditional cultural policy to include economic production, which is in a broad sense cultural and/or draws on individual talent and imagination, but which does not position itself predominantly as art-as web design, architecture, or video games, for instance. Visual and performing arts, music and literature suddenly find themselves amongst a much more heterogenic range of activities-a range for which, as researchers have repeatedly emphasised, it is difficult to pinpoint commonalities and shared identities (e.g. Garnham 2005, Hesmondhalgh 2007). Because engagement with any policy, cultural or otherwise, implies advocacy and because successful advocacy relies on a strong sense of identity and shared purpose, such diluting of identities is unlikely to be helpful for making the case for arts 
and culture, whatever the context or occasion. As illustrated by the above case of the gallery, a strong sense of shared purpose is essential for protecting or reclaiming the position of artistic practice in cultural production.

Secondly, the term innovation emphasises notions of usefulness, marketability and progress. Its omnipresence has helped embed a utilitarian perspective on the "wider" (read: socio-economic or just economic) contribution of creative, and therefore artistic or cultural, practice. It has normalised the view that such production leads to tangible and marketable progress (for instance, to innovation) and can therefore be presented and assessed in terms of how valuable a (contribution to) progress it delivers. The point here is not that the arts and culture are or should not be innovative-they can be and frequently are; but, as Oakley (2009) points out, it would be misleading to expect innovation to feature in every bit of cultural production. Similarly, artists and creative workers are of course able to propose social and political innovation.

artmoney.org, for instance, is an illustrative example of artists' "creative "problem-solving [...] with a more systematic and globally-oriented political agenda" (Banks 2013: 38). Indeed, an autonomist reading sees cultural work as the potential source of radical societal change and progress (Banks 2014). The problem of linking artistic and creative practice to innovation, progress and marketability lies in the refocusing on, and over-emphasis of, use value. Creative industries policy, with its utilitarian perspective on cultural production, draws attention away from the creative activity itself to the use of its product and, importantly, to the competent (read: versed in the policy language $d u$ jour) articulation of that use. It has claimed space-in public dialogue, on funding application forms and in the organisation of cultural production itself-for practices of economic engagement, and it has done so to the detriment of artistic practice itself.

It is because of these developments that the words "creativity and innovation" not only exasperate, but also bring out the pessimist in me. Creative industries policy, with its "creativity and innovation" mantra, has normalised the requirement of arts and culture to make a case for their useful/marketable/progressive contribution to society, and has forced them to do so in economic policy language and from a position of diluted identity. For sure, this requirement has been identified as problematic; it has been met with protest and discussion (e.g. Comunian 2009, O'Connor 2005), and some cultural leaders seem to find viable ways of responding to it (Webb 2014). However, this requirement has also resulted in subtle and less subtle, conscious and unconscious, changes to the balance of artistic practice, position-taking, and economic engagement in cultural production. Banks (2015) points out that because cultural value is a defining structural feature of cultural production, the commodification of art and culture depends on it as much as artistic practice itself does. While, as he concedes (ibid.: 43), "the economic order appears eminently 
capable of overriding cultural concerns', analyses should not accept such a hostile take-over as inevitable but explore how culture is 'counterposed, managed and arrayed in relation to the economic" (ibid.: 41, emphasis in the original). Understanding cultural production not as a juxta-positioning of the artistic and the economic, but as a ménage à trois of artistic practice, position-taking and economic practice can provide such a more nuanced analysis (Eikhof 2010). It reveals structural homologies between position-taking and economic logic that allow a hollowing out of artistic practice even against good intentions, even by regimes of commodification that recognise the economic value of cultural value. Neither the funder nor the art gallery in the above examples set out to destroy cultural value-most likely they genuinely attempted to preserve it. But embedded in and part of a discourse focused on creativity and innovation rather than arts and culture, their actions affected how artistic practice, position-taking and economic engagement relate to each other, and to the detriment of the first. The empirical examples cited above give little reason to join Oakley (2009: 410) in her hope that "for arts organisations [...] it may simply be a case of re-stating their value in another context." Even her assessment that "the danger is less to individual arts organisations and more to the ecology as a whole" appears optimistic. The long-term consequences of the creative industries-turn in cultural policy look to be severely problematic in terms of the vitality and sustainability of the arts and culture. Whether a rebalancing of the three main components of cultural production-artistic practice, position-taking and economic engagement-is possible or even likely, especially given contemporary austerity politics and funding cuts, is difficult to predict. My observations of cultural production, combined with Boltanski and Chiapello's (2006) demonstration of how capitalist, economic or business logics have annihilated other raisons d'être through integration, make me pessimistic. For art's sake, I hope I'm wrong. ${ }^{1}$

\section{References}

Banks, M. 2013, "Creative cities, counter-finance and the aesthetics of exchange: Copenhagen's artmoney project." Cities, 33: 36-42.

Banks, M. 2014, “'Being in the Zone' of Cultural Work." Culture Unbound, 6: 241-262.

Banks, M. 2015, "Valuing cultural industries." in K. Oakley and J. O'Connor (eds), The Routledge Companion to the Cultural Industries, London: Routledge, 35-44.

Bourdieu, P. 1983 "The field of cultural production, or: the economic world revised." Poetics, 12: 311-356.

\footnotetext{
1 The author would like to thank Kate Oakley and Mark Banks for their constructive comments and feedback.
} 
Carey, J. 2006, What good are the arts? London: Faber \& Faber.

Boltanski, L. and Chiapello, E. 2006, The new spirit of capitalism, London: Verso.

Chapain, C., Cooke, P., De Propris, L., MacNeill, S. and Mateos-Garcia, J. 2010 Creative clusters and innovation. Putting creativity on the map, London: Nesta.

Comunian, R. 2009, "Questioning creative work as driver of economic development: the case of Newcastle-Gateshead." Creative Industries Journal 2(1): 57-71.

Department for Culture, Media and Sport (DCMS) 2001, Creative industries mapping document, London: DCMS.

Eikhof, D.R. and Haunschild, A. 2007 "For art's sake! Artistic and economic logics in creative production." Journal of Organizational Behavior, 28(5): 523-38.

Eikhof, D.R. and Warhurst, C. 2013, "The promised land? Why social inequalities are systemic in the creative industries." Employee Relations, 35(5): 495 - 508.

Eikhof, D.R. and York, C. 2016 "'It's a tough drug to kick': A woman's career in broadcasting." Work, Employment and Society, forthcoming. Florida, R. 2004, The rise of the creative class, New York: Basic Books. Garnham, N. 2005, "From cultural to creative industries: An analysis of the implications of the 'creative industries' approach to arts and media policy making in the United Kingdom." International Journal of Cultural Policy, 11(1): 15-29.

Hesmondhalgh, D. 2007, The cultural industries, $2^{\text {nd }}$ ed. London: Sage.

Hesmondhalgh, D. and Pratt, A.C. 2005 "Cultural industries and cultural policy." International Journal of Cultural Policy, 11(1): 1-14.

Kantor, J. and Streitfeld, D. 2015 "Inside Amazon: Wrestling big ideas in a bruising workplace." The New York Times Online, http://www.nytimes.com/2015/08/16/technology/inside-amazonwrestling-big-ideas-in-a-bruising-workplace.html?smid=fb-share \& $\mathrm{r}=0$ [accessed 20/08/2015]

Landry, C. 2000, The creative city, London: Earthscan.

Menger, P.-M. 2013 "European cultural policies and the "creative industries" turn." in J. Chan and K. Thomas, Handbook of Research on Creativity, London: Edward Elgar.

Neate, R. 2014, “Berlin's "poor but sexy' appeal turning city into European Silicon Valley." The Guardian Online, http://www.theguardian.com/business/2014/jan/03/berlin-poor-sexysilicon-valley-microsoft-google [accessed 20/08/2015] 
Oakley, K. 2004, "Not so cool Britannia: the role of the creative industries in economic development." International Journal of Cultural Studies, 7(1): 67-77.

Oakley, K. 2009, "The disappearing arts: Creativity and innovation after the creative industries." International Journal of Cultural Policy, 15(4): 403-413.

Oakley, K., Hesmondhalgh, D., Lee, D. and Nisbett, M. 2014, "The national trust for talent?: NESTA and New Labour's cultural policy." British Politics, 9(3): 297-317.

O'Connor 2005, "Creative exports: Taking cultural industries to St Petersburg." International Journal of Cultural Policy, 11(1): 45-60.

Peck, J. 2005, "Struggling with the creative class." International Journal of Urban and Regional Research, 29(4): 740-770.

Rainnie, A. 2005, "Hurricane Florida: The false allure of the creative class." Sustaining Regions, 4(3): 4-9.

Walker, T. 2013, "Perks for employees and how Google changed the way we work (while waiting in line)." The Independent Online, http://www.independent.co.uk/news/world/americas/perks-foremployees-and-how-google-changed-the-way-we-work-while-waiting-inline-8830243.html

Warhurst, C. 2010, "The missing middle: Management in the creative industries." In Townley, B. and Beech, N. (eds), Managing Creativity, Cambridge: Cambridge University Press, 217-236.

Webb, A. 2014, "'We need arts as much as we need food. Our responsibility is for that to be possible': Insights from Scottish cultural leaders on the changing landscape of their work." Doctoral thesis, Stirling.

\section{The Zig Zag Path to Toy Story}

Keith Sawyer (University of North Carolina at Chapel Hill)

In creativity research, the predominant theories of how creativity occurs, and of how new ideas are generated, have been linear stage models, as summarized in (Sawyer, 2012, p. 89). Influential stage models include (Isaksen, Dorval \& Treffinger, 2000; Scott et al., 2004; Wallas, 1926). Perhaps the most widely cited linear models of creativity are versions of Wallas (1926) and include the following stages: 
- Preparation: The creator studies the history of prior works, concepts, and ideas related to his or her field.

- Incubation: The creator takes time off from the work, allowing ideas to potentially emerge from the subconscious mind.

- Ideation: One of more of these subconsciously formed ideas emerges into consciousness, often resulting in a subjective sensation of insight.

- Selection: Typically, the creator has many insights and as a result, many possible ideas to pursue. In the selection stage, the creator consciously analyzes each of the many insights that have emerged from the prior steps and chooses which one will be most promising to pursue.

- Execution: The selected idea is developed, using the established practices and methodologies of the creator's field, to a point where a work can be publicly shared. (Wallas, 1926, combines selection and execution in a "verification" stage.)

Linear theories of creativity and innovation tend to reinforce two common beliefs about creativity. The first is that creativity is based in a surprising, sudden moment of insight. In the ideation stage, an idea is thought to emerge from the subconscious mind, and in the selection stage, the creator realizes its importance. The second is the belief that creativity is driven by solitary, lone individuals. After all, it's people that pass through this process while working, it's people who have creative ideas, and they're more likely to have these insights when they're alone.

If innovation is based in creative people having great ideas, then the implication for organizations is to make sure that recruiting and hiring practices identify creative individuals; and to make sure that staff development programs are designed to enhance each employee's creativity. Another implication is that employees should be rewarded for good ideas-for example, by implementing profit sharing programs, or bonuses for ideas that come to fruition and generate revenue.

But most companies have found that these techniques do surprisingly little to enhance organizational innovation. The reason is that linear theories of creativity are wrong. Instead, research has shown that the creative process unfolds unpredictably (Sawyer, 2007, 2012). It emerges from a wandering, exploratory process, and unexpected ideas slowly advance the process. This meandering path leads down many dead ends; this is why successful innovators so often talk about the importance of frequent failure. I use the term zig zag to characterize the creative process. The term "zig zag" is meant to invoke the image of a zig-zagging line, which takes sudden turns and often shifts direction (Sawyer, 2013).

In a related set of findings, research has shown that successful 
innovation is not based in moments of sudden insight, and it is not the result of individuals having great ideas. Instead, innovation emerges from collaborations among individuals-from small sparks, tiny ideas, that come together in effective teams and social networks. Innovation is not about individuals; it is an organization-level phenomenon (Sawyer, 2007).

The most innovative companies are the ones that have been able to overcome these all-too-common, stereotypical beliefs about creativity, and have come to understand its slow, incremental, and collaborative nature. They've designed their culture, structure, and incentives to align with this creativity research. Such companies include legendary innovation powerhouses like W. L. Gore, Google, and 3M. In this paper, I'll describe how this works at Pixar.

I'll start with a case study, the successful innovation that put Pixar on the map. In November 1995, Disney released Pixar's Toy Story, the first-ever movie that was 100 percent generated with computer animation. It was a huge risk; in fall of 1994, even Pixar's owner, Steve Jobs, was about to give up and sell the company to Microsoft. But the risk paid off big-time: The movie's reviews were astonishingly good. The Washington Post compared it to 1939's The Wizard of Oz. The movie grossed \$28 million on its opening weekend, the most successful Thanksgiving weekend movie opening ever. It went on to become the highest-grossing movie of 1995 , with $\$ 192$ million U.S. box office and $\$ 357$ million globally.

The plot, you'd think, must have come from a burst of inspiration. A little boy named Andy plays in his bedroom with his toys, especially his favorite wooden cowboy doll named "Woody." At Andy's next birthday, his favorite present is a new action figure of a spaceman, Buzz Lightyear. Buzz quickly becomes Andy's favorite toy, and Woody gets really jealous. While on a family trip to a pizza restaurant, the two toys get into a fight and fall out of the family car, getting left behind. They go through a series of adventures and challenges to find their way back to Andy's house, and have to face off against Andy's mean neighbor Sid Phillips and his evil dog Scud. At the end of the movie, they are finally reunited with Andy and his other toys.

But the plot did not come from a burst of inspiration. Instead, it emerged from a long creative process that resembled a zig-zagging path. The original treatment for Toy Story, written by John Lasseter, Andrew Stanton, and Pete Doctor, had almost nothing in common with the movie that we know and love. Let's follow the zigs and zags of the creative journey that led to Toy Story (Price, 2008, pp. 121-132).

Zig: The first draft was ready in March 1991. It had two main characters: a one-man band named Tinny and a ventriloquist's dummy. The movie starts with Tinny waking up in his factory, and then he is given as a birthday gift to a young boy. The boy's family goes on a road trip to the Southwest, and they take Tinny along. But early in the trip, he gets 
forgotten and left behind at a gas station. There, he meets the ventriloquist's dummy, and they work together to find their way back to Tinny's home. In a series of adventures, the two travel from the back of a truck to an auction, to a garbage truck, a yard sale, a couple's house, and finally to a kindergarten playground-the happy ending in which the toys are reunited with the children.

Pretty much the only plot element that made it into the final movie was a toy getting left behind at a gas station. Other bits and pieces zigged and zagged into the final movie: a Slinky caterpillar in the treatment gradually evolved into a Slinky dog in the final film, and in both treatment and film, there's a threatening pet dog that the toys have to escape from, and one of the main toys is given as a birthday present.

Zag: After the initial treatment, Jeffrey Katzenberg of Disney told Pixar to rewrite Toy Story as more of an odd-couple buddy movie-like the older movie The Defiant Ones, about two men thrown together by circumstance and forced to cooperate even though they hated each other. So in September 1991, the Pixar team came back with a second treatment. Tinny and the dummy were still the main characters, but there'd been lots of changes. Tinny was no longer born in the factory; he was born as he was unwrapped. The ventriloquist's dummy was already in the house, and it was the children's favorite toy. The dummy became jealous of the shiny new Tinny, and they started to argue with each other.

Instead of a vacation to the Southwest, the family was moving to a new town, and after a hard day of packing, they went out for pizza. The favorite toys went along for the ride, but they fell out of the car at the gas station and got left behind. Eventually they made it back home, but the moving van was just leaving for their new town. Tinny and the dummy were deterred by a vicious dog, but then all of the toys helped rescue Tinny from the dog, and Tinny and the dummy were happily reunited with the family.

Zig: The next zig came when Lasseter decided that Tinny was too old-fashioned. He replaced Tinny with a G.I. Joe type action figure.

Zag: Lasseter changed the action figure character into a space hero named Lunar Larry.

Zig: His name was changed again, to Tempus from Morph, and his outfit was changed to a bright red space suit.

Zag: The dummy was transformed into a cowboy character, exaggerating the contrast between the new space hero and the boy's old favorite toy.

Zig: Disney nixed the ventriloquist dummy character. They were worried that parents (and children) would find it creepy and scary; a lot of horror movies use the ventriloquist dummy as an evil and dangerous character. Woody was changed into a stuffed toy with a pull string. 
Zag: Tempus was renamed Buzz Lightyear.

Zig: Pixar wanted G.I. Joe as one of the toys in the movie, but Hasbro refused to license the rights, instead granting permission only for Mr. Potato Head.

Zag: The writers decided that Woody and Buzz would be rescued from Sid's house by Barbie in a commando style raid, patterned after Sarah Connor in Terminator 2.

Zig: This idea was dropped when Mattel refused to license the rights to Barbie.

Zag: Pixar wanted Billy Crystal to play Buzz, but he turned down the part. The next choice was Tim Allen, star of the TV show Home Improvement. The directors had wanted Buzz to be a self-important, almost arrogant character, and Billy Crystal could have done this voice brilliantly. But at the first script reading, Allen's voice made Buzz sound like a friendly, ordinary guy-and the directors decided they liked that version of Buzz even better.

Zig: In November 1993, this back-and-forth journey culminated in yet another rejection by Disney. The biggest problem was that Woody was too unlikable: An early scene had him abusing Slinky Dog, and another had him pushing Buzz out the window. Pixar rewrote the script to make Woody more sympathetic. Instead of pushing Buzz out the window, Buzz fell by accident.

Finally in February 1994-three years after the original treatment-Disney gave the green light. Production would start that April.

Toy Story offers several lessons about creativity:

1. The first idea won't be great. It's likely to be substantially modified, or to be removed altogether. But the first idea is necessary to get the journey started.

2. Creators never know exactly where they are in the process; they don't know how close they are to the final goal. But they trust that the process will eventually lead to successful creativity.

3. Each zig leads to the next zag, and these changes in direction drive the creative process forward.

Even after many subsequent successful movies, and with bigger and bigger budgets from Disney (and correspondingly bigger risks), Pixar has stayed true to its grounding in this improvisation, wandering process. This includes more recent hits such as Frozen and Inside Out (Catmull and Wallace, 2014; Barnes, 2015).

In business and entrepreneurship today, shifts in direction are often called a "pivot" (e.g., Ries, 2011). But this term makes it sound like all you need is one major transition, when in reality, successful innovation 
involves constant, frequent shifts in direction. So I prefer to call each turn a "zig zag" and my image of the process is a zig-zagging line, with frequent changes along the way.

I am often asked to provide advice on innovation to business organizations. Many of these organizations have senior managers who've figured out the truth about innovation. Their challenge is to convince the rest of the senior leadership, and then the staff of the organization. It's a major transformation, because it requires a new culture, new incentives, and a new leadership style. My role is to support these efforts by showing that the transformation is grounded in solid scientific research.

Unfortunately, most organizations that need innovation consulting are far from finding innovation. In these, I'm asked to present a "business process model" or a scientifically-based linear pathway that has been demonstrated to increase the odds that revenue-generating products will emerge. The senior leadership team is looking for certainty and predictability. I do my best, but all too often, these organizations never change. They never become innovative, because they're not ready for the necessary transformations.

Traditional management techniques can work well for incremental innovation-when you make minor modifications to existing successful products, or you take an existing product and attempt to sell it to a new demographic, or in a new country. But for radical innovation-new products or services that result in market-leading breakthroughs, and large profit margins, and strong brand identity, organizations need a transformation that aligns with the natural process of innovation. It's difficult to succeed at this sort of innovation, because it requires that six organizational characteristics be in alignment:

1. Culture: Innovative organizations have a culture that supports risk taking, that acknowledges the importance of failure, and that fosters collaboration and broad-ranging social networks

2. Process: Innovative organizations support the wandering, zig-zagging process of creativity. Although the process is unpredictable and non-linear, there are roughly eight phases of creativity that occur at various points in the process (see Sawyer, 2013). Successful innovative organizations provide support for all eight of these phases.

3. Incentives: One common mistake is for organizations to reward success; but creativity often involves failure, and the failures can be essential to the eventual success. A second mistake is for organizations to reward the individuals thought to be responsible for the innovation, when in fact, successful innovations emerge from many contributions from many individuals, and for some of them it's hard to explicitly 
identify exactly what their contribution was. Rewarding specific individuals blocks the collaboration and openness that drive innovation.

4. Composition: Creativity research has found that when teams and organizations are composed of people with different backgrounds, they are more innovative. The type of diversity that works best is cognitive diversity: people who come with different intellectual backgrounds, and who have mastered different bodies of facts and conceptual material. Having a diversity of skin color or nationality or ethnic background won't work as well, if everyone has the same degree from the same university.

5. Leadership: In innovative organizations, leaders understand that innovation emerges from the bottom up: from diffuse networks of collaborating individuals. Leaders understand that innovations are unpredictable and that the process is non-linear. Leaders realize that they are not the ones who can develop, alone, a successful innovation. In addition, research shows that decisions about which innovations to pursue are more effective if they're made by a distributed team, rather than by a single executive. In innovative organizations, leadership is distributed rather than concentrated in a powerful executive.

6. Structure: Innovative organizations have complex structures. Individuals often participate in multiple projects, sometimes in very different market segments and functional units. In the most innovative organizations, individuals change units and assignments frequently. This drives innovation because it helps to distribute knowledge across cognitive frameworks and organizational lines.

For successful innovation, an organization needs to have all six of these characteristics. Getting any one of the six wrong can derail the natural process of successful innovation-the wandering, improvisational process that I call a zigzag. Research shows that organizations can make the transformation, and we know a lot about how to help organizations along the path from traditional organizational structures and cultures, to new forms that drive innovation.

\section{References}

Barnes, B. 2015. The brain behind Pixar's new film. The New York Times, pp. AR1, AR10. Sunday, May 24.

Catmull, E., \& Wallace, A. 2014. Creativity Inc.: Overcoming the unseen forces that stand in the way of true inspiration. New York: Random House. 
Isaksen, S. G., Dorval, K. B., \& Treffinger, D. J. 2000. Creative approaches to problem solving: A framework for change (Second edition). Buffalo, NY: Creative Problem Solving Group.

Price, D. A. 2008. The Pixar touch: The making of a company. New York: Knopf.

Ries, E. 2011. The lean startup: How today's entrepreneurs use continuous innovation to create radically successful businesses. New York: Crown Business.

Sawyer, R. K. 2007. Group genius: The creative power of collaboration. New York: BasicBooks.

Sawyer, R. K. 2012. Explaining creativity: The science of human innovation (2nd edition). New York: Oxford.

Sawyer, R. K. 2013. Zig Zag: The surprising path to greater creativity. San Francisco, CA: Jossey-Bass.

Scott, G., Leritz, L. E., \& Mumford, M. D. 2004. The effectiveness of creativity training: A quantitative review. Creativity Research Journal, 16(4), 361-388.

Wallas, G. 1926. The art of thought. New York: Harcourt, Brace and Company.

\section{"Here's to the Crazy Ones": Why We Need to Rethink "Fitting In" as a Virtue in Innovation-based Business and Society}

Robert D. Austin (Copenhagen Business School, Denmark)

Recently, I gave a talk about what I think organizations need to do be become more innovative to a group of Human Resource Management (HRM) executives, at a conference designed specifically for people who occupy such positions. The reaction was interesting. They were polite. A handful of people were clearly excited by what I was saying, nodding, some almost cheering, though quietly. But the overall reaction was silence, distrust, apprehension. Alas, what I had to say was not very much like what they were hearing in the other conference sessions.

More specifically, I was talking about a project I've grown increasingly engaged in in recent years, about neurodiversity in the work force, how it benefits innovation, and how more and more companies and other organizations are giving it a try. But it was not neurodiversity per se that these HR execs had a problem with. It was something broader, an 
apparent implication of my more specific points. Allow me to explain by working up to that broader implication.

My involvement in the neurodiversity movement-for it has become, now, a movement-started back in 2007, when I co-wrote a Harvard Business School case about a Danish company called Specialisterne (Austin, et al, 2008). Thorkil Sonne, the founder of Specialisterne-which means "The Specialists" in Danish-had the audacious idea that some people with autism might have special abilities useful in the IT industry. Motivated by events in his own life, notably his son's autism diagnosis, Thorkil refinanced his home and used the cash he freed up to start a company that would sell software testing services. He had the idea, which turned out to be right, that some people on the autism spectrum would be really good at the exacting but often extremely repetitive tasks involved in software testing, quality assurance, and similar kinds of work. The movement he started has grown by leaps and bounds, achieving a major milestone in April of 2015 with a United Nations event called "Employment: The Autism Advantage." Thorkil has now branched out and not only offers software testing services, but has also begun helping large companies start their own neurodiversity programs. SAP has been a pioneer, as has Hewlett-Packard.

Early on, Sonne adopted the dandelion as the symbol of Specialisterne. The dandelion is, of course, that self-propagating yellow flower with ugly jagged leaves that many keepers of beautiful lawns have learned to detest. As a child, I remember my father's vehement efforts to eradicate these yellow interruptions in the uniformly green natural carpet he was trying to cultivate in front of our house. It's difficult, because they reproduce and replant themselves quickly, and they are hardy-you have to get the root out, or they'll come back.

What Thorkil points out, in a truly poetic metaphor, is that the dandelion, viewed on its own, is a very valuable plant. It can be used to make wine, tea, and coffee and its leaves are a nutritious addition to a salad (it's a source of vitamin A, calcium, potassium, iron, manganese). It contains an inflammation reducer that some scientists in Canada are investigating as a possible cancer cure (see references). So what makes the plant a much hated weed? What makes it a weed is the context, the fact that it ends up in the wrong place-in what is intended to be a uniformly green lawn. The analogy, of course, is to Thorkil's staff with autism-they are very valuable people, but get labelled as the societal equivalents of weeds when we try to force-fit them into the narrow, predefined roles of standard organization charts. If we can locate them in a better place, in a context that accommodates their individual needs and activates their talents fully, then they need not be weeds at all. This is what Thorkil has proven, with Specialsterne, and what other companies like SAP and HP are piling up evidence to support.

This idea extends, both conceptually and in practice, into a 
broader idea, which Thorkil and I have called "The Dandelion Principle" (Austin and Sonne, 2014). The dandelion principle asserts that it will often be, on the whole, beneficial to an organization to adjust the contexts of work to activate the talents of workers more fully, and to abandon the expectation that we should choose people to fit pre-defined standard roles. As managers in our study of "dandelion programs" have told us repeatedly, the approach that they must bring to their employees with autism-providing individual accommodations and adjusted contexts that activate their talents-teaches managers to achieve better results with their other, more neurotypical employees. Working within standard organizational roles prompts employees to do good work, but individual accommodations make them more likely to do great work.

Here we begin to come close to the implication that made the HR managers squirm. The dandelion principle says we should NOT start in hiring with checklists derived from a top down strategy process, as is called for in "strategic HRM" textbooks. Instead, hire people with special abilities, and put them into an individually designed context that maximally activates their talents. What's threatening to conventional HR thinking about this line of logic, is that it calls on us, at least to some extent, to reconsider long cherished ideas about the virtues of fitting in. As the moderator after my talk noted, HR execs are always trying to fit people "into the grid" and those who don't fit don't get hired.

For a long time, people with autism have suffered exactly this fate. You might have dual Masters degrees in electrical engineering and computer science, but if your interviewer can't check the box that says "makes good eye contact," you're toast. ${ }^{2}$ This problem afflicts not just people with autism, but many others with "differences." As a manager in my pre-academic career, I once had a brilliant contract employee who had a very obvious social anxiety issue; as brilliant as he was, he would fall to pieces in interview situations, or situations in which he had to talk to more than about three people. The company I worked for really needed to hire him, because his knowledge of our computer systems was encyclopedic and his software development talent immense. Repeatedly, I tried to get him hired. But he could never successfully run the HR checklist gauntlet.

What I was saying, then, to a group of HR managers, is that the way we do HR in companies means we're losing out on a lot of talent. Of course, this is what made them uncomfortable. Much of what they were talking about in other conference sessions, their "grids" and such, were obstacles-or so I was saying-to their companies" long term success.

But I haven't yet tied this problem back to innovation. The

2 Autism spectrum disorder is often characterized by social interaction difficulties. So it is exactly things like "making eye contact," or awkward or blunt verbal interaction, that cause problems for people "on the spectrum." 
motivation that SAP stated at the launch of their "Autism@Work" program in May of 2013, makes the connection explicit:

"We share a common belief that innovation comes from the "edges." Only by employing people who think differently and spark innovation will SAP be prepared to handle the challenges of the 21st century." (SAP press release)

They did not say "we want to show that we're good corporate citizens," or "we hope to score great CSR points" (although they have certainly done some of that-other than Specialisterne, no company got more favorable mentions at the UN event than SAP). They said, in essence, "we need neurodiversity to innovate and survive competitively." The company thinks similarly about other kinds of diversity. With more than 70,000 employees from more than 90 countries, they are in the diversity game in a big way. Visit an SAP cafeteria, which I did this summer in Palo Alto, California, and you'll encounter a marvelous array of talents from all around the world.

The logic behind the claim that diversity leads to innovation is straightforward. Innovation requires-I'm borrowing from Don Campbell, 1960 here-that we:

1. Create variants different from what we have created in the past, and

2. "Selectively retain" valuable variants, sorting variants we think might be valuable apart from those we don't think promise value, pursuing the former and setting aside the latter.

Campbell's framework is Darwin-inspired: variation + selective retention. People and organizations have problems in both parts of this equation. At stage one, we have a tendency to create new things that much resemble the old things we've created before. At stage two, we have a tendency to see value in new things that much resemble what we've seen and experienced value in before. It's probably not accidental that, of all the wondrous things Xerox researchers invented at their Palo Alto Research Center (PARC) in the early 1970s, the one thing they most successfully commercialized was the laser printer-the device that's arguably most like a Xerox machine.

Diversity, then, or so the argument goes, is likely the help with the problems of both stages. Different backgrounds, disciplinary training, neural wiring, and so make it more likely that you'll come up with a variant different from what has come up in the past. And the different points of view that derive from differences make it more likely that you'll see value coming from new directions.

Innovation is about producing valuable inconsistency. But it can be difficult to be inconsistent within organizations that have, for years, worked to shrink variation, using techniques like Six Sigma. Valuable 
inconsistency arises, not at the center of the probability distribution, where industrial approaches have often focused, to align means and shrink variances, but at the edges. In an innovation economy, we need variance. We need the outlier ideas, and to get those, we might just need more outlier people-more oddballs, more misfits.

This is not an entirely new notion in the tech industry. On a panel I facilitated a few years ago, a venture capitalist had this to say:

"I worked at [a major tech company] for thirteen years and had a chance to work on many of the great businesses there...At the core of every great product...you'd often find a very capable individual...And these guys-no offense to them-but they're all a little odd....they have their own...let's call them "inspired peculiarities'...They all extract a tax from the organization in the way that they work...they're different from other people, in a way that doesn't fit very well sometimes...but if you're at the core of product, you can extract a pretty high tax, and that's okay, it's good for the company..."

An iconic Apple television advertisement makes a similar point:

Here's to the crazy ones. The misfits. The rebels. The troublemakers. The round pegs in the square holes. The ones who see things differently. They're not fond of rules. And they have no respect for the status quo...they change things. They push the human race forward. And while some may see them as the crazy ones, we see genius. Because the people who are crazy enough to think they can change the world, are the ones who do.

Indeed, the odd ball nerd who achieves seemingly unexpected success is now an enduring motif within the tech industry.

Is there empirical research to support this notion? Some. This is the point of research we're currently engaged in with SAP and HP; and although we are not there yet, I believe based on what we've seen already, that we will be able verify the dandelion principle-we will show the net benefit, in terms of innovation and other payoffs, of neurodiversity, at least in these companies. One revelation at this point has been that participants in the program have proven suitable for a much wider range of jobs than anticipated; at SAP, the mathematical inclinations that some people on the spectrum exhibit have been useful in data analytics and digital security work that the company has trouble finding people qualified to do.

Other recent research is suggestively supportive also. For example, in a study of crowdsourcing, Jeppesen and Lakhani (2010) have shown that "marginality" is statistically related to success in solving scientific problems. They analyzed "solvers" on the InnoCentive crowdsourcing platform and found that successful solvers are typically distant from the "focal field of the problem." They noted that you could 
extrapolate this finding to suggest that "the best way to solve problems is to have experts from vastly different fields attempt solutions" (although they also urged caution with extrapolation of their findings to extremes). This is disciplinary diversity, not neurodiversity, but the principle might be quite general.

Work by Lakhani and some others suggests that, while traditional workers in traditional organizations can be very reliable in producing pretty good new ideas, marginal people are more likely to come up with really great new ideas. And you could argue, further, that in an increasingly "winner take all" oriented economy (Frank and Cook, 1996), an organization's ability to come up with great ideas might be of increasing importance.

But this is bound to cause heartburn for traditional HR (and other) managers. My favorite expression of just what might be implied by a society that reveres outliers to a much greater extent is a rant by cyberpunk writer Bruce Sterling, an exhortation to fellow "nerds":

"Forget trying to pass for normal. Follow your geekdom. Embrace nerditude... Don't aim to be civilized. Don't hope that straight people will keep you on as some sort of pet. To hell with them....take a terrible revenge. Get weird. Get way weird. Get dangerously weird. Get sophisticatedly, thoroughly weird, and don't do it halfway...Don't become a well-rounded person. Wellrounded people are smooth and dull. Become a thoroughly spiky person. Grow spikes from every angle. Stick in their throats like a pufferfish."

Imagine managing employees with this attitude. Some people, especially in the tech industry, don't have to imagine it. They have been there. My contention: more people need to go there. But the way we do HR today is pretty much completely opposed to going where we need to go and the future innovation economy. The "tax" that someone like this might extract from an organization, as the VC I mentioned earlier put it, could be quite high, and traditional HR aims to avoid such taxes, often by choosing people who "fit in."

The fundamental difficulty with Human Resource Management as often practiced is, as Thorkil and I have expressed it, this:

The phrase "human resources" suggests that there's valuable "human stuff" that companies just happen to keep stored in containers called "people." This is kind of like referring to the contents of a famous art museum as "paint resources" (Austin and Sonne, 2014).

People are not fungible resources. Jose Velasco, the U.S. lead of SAP's Autism@Work program, likes to say that people are like puzzle pieces. Each one has a different shape. And with a lot of hard work, we can piece them together into an effective whole. But in organizations we have often 
taken a short cut. We've designed roles that, in essence, cut off people's odd shaped edges so that each puzzle piece has a regular, rectangular shape, one that fits easily together. But, as Anka Wittenberg, SAP's Chief Diversity and Inclusion Officer notes, there's a big drawback to this:

"Our vision is to create an inclusive environment where people can bring their uniqueness to the table. The corporate world has mostly missed out on this. Historically, we've asked people to tailor themselves to fit. But when you do that, people have to leave part of their authentic selves behind, which is too bad because those parts are potentially valuable to us."

To put it simply: in an innovation economy, fitting in is over-rated. And we need to re-examine our practices in business to take this into account, especially our HR practices. There has never been a time when we more needed to solve this problem, or when we were better positioned to do it. Here's to the crazy ones. Let's bring more of them on board.

\section{References}

"Cancer-killing dandelion tea gets $\$ 157 \mathrm{~K}$ research grant," CBC, April 20, 2012, http://www.cbc.ca/news/canada/windsor/cancer-killingdandelion-tea-gets-157k-research-grant-1.1248382

Austin, R. D. and T. Sonne. 2014. "The Dandelion Principle: Redesigning Work for the Innovation Economy," MIT Sloan Management Review.

Austin, R. D., Wareham, J. and J. Busquets. 2008. "Specialisterne: Sense and Details," Harvard Business School case number 608-109, February, 2008.

Campbell D.T. 1960. "Blind Variation and Selective Retention in Creative Thought," Psychological Review 67: 380-400.

Frank, R. H. and P. J. Cook. 1996 The Winner-Take-All Society: Why the Few at the Top Get So Much More Than the Rest of Us. New York: Penguin.

Jeppesen, L. B., and K. R. Lakhani. 2010. "Marginality and Problem-Solving Effectiveness in Broadcast Search.” Organization Science 21 (5): 10161033. 


\section{Creativity in a Real-Time World: Improvisation and the Culture of Creativity}

Peter Johnson (Fordham University, New York)

As technology accelerates and competition intensifies, innovation has become a priority in almost every business strategy. "The fear of getting Netflix-ed or Uber-ized is spurring big companies to dial up their investment in innovation." Accelerators, incubators and innovation teams are being formed everywhere and one of the newest top job titles is Chief Innovation Officer (Kirsner 2015). Yet, one of the great ironies of a formally structured innovation process is that creativity often is highly unstructured, nonlinear, serendipitous and "more closely associated with art than it is with science" (Edwards 2008). With this paradox of structure versus creativity, perhaps it is no surprise that many resourceful businesses are using a process derived from performing arts which has been found to accelerate innovation, foster creativity, and improve communications. And, interestingly, this process already occurs organically in almost every organization (Moorman and Miner 1998a 1998b, Cuna, et al. 2012)

\section{Organizational improvisation: a catalyst for creativity and innovation}

When we think about "improvisation" the concept most often evokes images of standup comedy or a jazz combo. But before you start booking an offsite workshop at the Upright Citizens Brigade or Second City, it is helpful to take a look at what "organizational improvisation" actually entails and how it is winning applause for business innovation.

Although is a relatively new concept in managerial science, organizational improvisation has a long-standing and valued role in music and performing arts (Crossan 1998; Hatch 1998; Randall 1993; Vera and Crossan 2004; Weick 1993, 1998). The word improvisation comes from the Latin and is a combination of proviso and the prefix im. Proviso means to provide for something in advance or do something that is premeditated. When the prefix "im" is added, the word becomes definitional opposite, as in the word "immobile." Thus improvisation (improvisus) is used to describe "that which is unforeseen and the unexpected" (Weick 1998)-an apt description of business situations that managers face every day.

As evidenced in its Latin roots, improvisation has been around for a long time. It has been taught and performed in theater and music as far back as the 18th century (Randall 1993). Beethoven and Mozart were known as accomplished improvisers and many of their improvisational creations were later written down and used as the basis for classic 
symphonic themes. (Berkowitz 2009; Gibson 2006; Hatch 1998). In business literature, the jazz metaphor has been frequently used to conceptualize organizational improvisation. A jazz combo has instrumentation (skill sets), an audience (customers), a venue, a time frame and predetermined themes. But within these confines the participants are encouraged and expected to create, experiment, and build on each other. At times they rely on standard patterns; at other times solos, duets and other combinations take off and discover new and unexpected directions (Crossan 1998; Hatch 1998).

The process of improvisation also is accepted and routinely employed in non-artistic fields that include athletics (Mirvis 1998) and the military (Brady 2011; Senor and Singer 2009). In athletics, the managers (coaches) and workers (athletes) go through extensive physical and mental training and endure long hours of repetitive practice. Then, in actual competition, teams start with set plays and then are expected to improvise to gain advantage over an opponent (Gilmore and Gilson 2007). As many football coaches will attest, the structure of a set play lasts for no more than a few seconds and, after that, success depends on how players react to unanticipated moves from the opposing team and improvise solutions to each unique situation. Modern military doctrine also values improvisation. Along with extensive training, deep enculturation and a formal hierarchical structure, today's military places a high value on initiative and real-time response in actual combat (Brady 2011; Warfighting 1994).

Improvisation covers a wide range of activities and can be conducted by individuals, groups, and organizations. Examples of individual improvisation would include soliloquies, musical solos, or modern dance. (Crossan 2004, Hatch 1998). Group improvisation might include a theatrical cast, crisis managers (Weick 1988, 1993), athletic teams (Mirvis 1998), emergency rooms (Batista and Cunha. 2009) and service recovery (Cunha and Kamoche 2009). In everyday business situations "organizational improvisation" occurs frequently in small units of existing behavior which can include work groups, cross functional teams-and even spontaneous hallway conversations (Crossan and Apaydin 2010; Moorman and Miner 1998a, 1998b).

To more clearly identify organizational improvisation in a business context, a number of definitions may be helpful. One of the simplest ones (Kamoche and Cunha 2001) defines improvisation as "the art of composing and performing contemporaneously." (Note the use of the word "art.") Another definition adds the use of experience and resources: "the conception of action as it unfolds... drawing on available material, cognitive, affective, and social resources." The definition of improvisation perhaps most often used in business applications adds the dimension of time to define improvisation as "the degree to which composition and execution converge in time" (Moorman and Miner 
1998a). Improvisation can also be proactive or reactive. In reactive situations, participants are forced by events to act quickly without the benefit of time or fixed strategy. In other cases, such as theatrical performance or even a new product initiative, groups agree ahead of time to improvise and follow its guidelines of improvisational behavior (Akgun et al. 2007). As performers know, improvisation is a skill that can be practiced and learned (Halpern et al. 1994; Mirvis 1998) and, when used properly in business, it gives managers a set of tools to respond quickly to unexpected situations, to improve responsiveness, and to minimize the use of resources (Vera and Crossan 2005).

\section{Expect the unexpected}

In practice, virtually all managers will have to use improvisation, whether they are trained in it or not. Drastic changes in deadlines, demanding clients and out-of-the-blue dot com competition (like Uber) are all examples of business situations where improvisational actions may be the most readily available alternative (Moorman and Miner 2001; Weick 1998, 1993; Weick et al. 2005). Improvisational situations can be recognized when managers say things like: "we're going to have to wing it," "doing it on the fly," "shooting from the hip," or other phrases that describe a process that demands innovation in real time (Crossan et al 2005).

Two high-profile events are examples of organizational improvisation being used to deal with fast-moving business situations. In 2008, when facing the near collapse of the US banking system, secretary of the treasury, Henry Paulson, and chairman of the Federal Reserve Bank, Ben Bernanke, acting in less than three days, developed a threepage proposal to demand an immediate $\$ 700$ billion from Congress to purchase toxic assets. Mr. Paulson, a highly experienced business executive and the former chairman of Goldman Sachs, apologized for the brief length of the document given the staggering amount of money requested. Although he had over 35 years of high-level business experience, Mr. Paulson told Congress: "There is no playbook for responding to turmoil we have never faced. We adjusted our strategy to reflect the facts of a severe market crisis, always keeping focused on our goal to stabilize the financial system" (New York Times 2008). What Paulson and Bernanke did was to improvise a creative solution, although it is likely neither one of them, even with all their experience, had ever been trained in improvisation.

Another example occurred in 2010, when BP was struggling to control the disastrous oil spill in the Gulf of Mexico. Richard Sears, the head of offshore oil exploration for Shell and an MIT professor who was working day and night to create a solution said: "There is no standard operating procedure for these kinds of incidents. That would be because they don't happen very often.... [It's] all custom solutions" (Popular 
Mechanics, May 24, 2010). Then, after the spill was controlled, BP calculated billions of dollars in compensation to businesses and individuals in "real time" without benefit of a formal corporate strategy (Aldy 2011).

Use of improvisation to innovate and find solutions need not be of the magnitude of these two crises. In research conducted by the author, when managers were in situations where they had to improvise, they cited circumstances like: a sudden, large new business opportunity; drastic actions by competitors; new product launches arbitrarily accelerated by management; or new technology adaptation, such as migration to mobile devices. These examples, along with the body of organizational literature, indicate that, while improvisation may not be an explicit part of most business strategy preparation, it almost inevitably will be needed (Weick 1998).

\section{Good news: improvisation seems to produce better results}

Just as not all theatrical or musical improvisations produce enduring art, organizational improvisation does not always guarantee success.

However, there is significant evidence that organizations that encourage and support improvisation, on balance, get productive results. Moorman and Miner (1998a) found that in a new product development situation, even among organizations with highly formal procedures, improvisation occurs frequently. And in times of high economic turbulence, higher levels of organizational improvisation had a significantly positive effect on new product performance. Organizational improvisation also can be enhanced with training. Vera Crossan (2005) found that the application of improvisational techniques like, "agree, except, and add" and "readymades" in an organizational setting produced behavioral changes that enhanced performance. But can improvisation develop creativity and innovation that lead to better overall business performance? 


\section{Organizational improvisation has a positive relationship to business performance, as quantified by market orientation}

For over 20 years the concept of "market orientation" has been associated with positive organizational performance (Jaworski and Kohli 1993; Kirca, Jayachandran, and Bearden 2005; Kohli and Jawarski 1990; Narver and Slater 1990). Over 200 academic studies have quantified that companies that have higher market orientation produce better marketing, financial and customer results. But, to achieve and sustain market orientation requires businesses to be highly sensitive to customers, responsive to competition, and have efficient internal communications. Not all businesses are market oriented-and to maintain it requires continuous innovation and dedication of resources (Ketchen et al. 2007; Kumar et al. 2011).

As innovation is an important part of building and sustaining market orientation, a theory has been developed that the spontaneity and creativity of organizational improvisation might be interconnected with market orientation (Baker Sinkula 1999; Dennis and Macaulay 2007). The author found that this idea resonated with a number of senior business executives who, although highly experienced, often found themselves facing situations where they needed to innovate and create solutions with little time and no set structure. This motivated an empirical study to examine if there were a measurable relationship between top management work groups, that exhibited higher levels of organizational improvisation, and the market orientation of their firms. The results of this research were both expected-and surprising.

The expected part was that, confirming similar studies, organizational improvisation has a positive impact on market orientation. In a study of 234 top managers, it was found that $24.3 \%$ of market orientation could be explained by the variable of organizational improvisation (Johnson 2015). The more surprising finding of this research was that this positive relationship was not moderated to any significant degree by job title, seniority, size of company, type of industry, or gender. While we expected to see a positive relationship between improvisation and market orientation in small businesses and technology companies, the same positive relationship was present in large financial service companies, manufacturers, and among senior executives. These findings set up some interesting implications for business creativity and innovation. 
There's a commonly held belief that creativity and innovation are ingrained in corporate culture and that certain organizations, such as ad agencies and technology startups, are simply more innovative-and perhaps more improvisational-than large, established firms. However, examination of organizational improvisation and the body of research indicates that this may not be the case. It seems that innovation comes on the workgroup level and, perhaps more importantly, the opportunities to improvise are frequent and have the potential to be productive.

\section{It's not a matter of if you need to improvise; it's a matter of when}

As managers continue to be pressured to innovate, perhaps they do not have to reinvent their culture or invest in elaborate structures.

Improvisation already occurs organically in all organizations, so why not anticipate it, train managers in its use and welcome it as part of the innovation process? An important side benefit to this is that there is comparatively little cost in recognizing and supporting improvisation. Businesses can simply take advantages of situations that inevitably will occur to encourage group coordination and creativity. The research indicates that improvisation is not just "winging it" and hoping for the best. Improvisation is a proven and respected practice in the arts and it is inevitable in a fast-moving business world. In addition to structured investments in innovation, executives may be well served to train their teams in improvisation, practice it when it occurs, and know that in many cases improvisation produces innovative and positive results.

\section{References}

Akgun, Ali E., John C. Byrne, Gary S. Lynn, and Halit Keskin. 2007. "New Product Development in Turbulent Environments: Impact of Improvisation and Unlearning on New Product Performance." Journal of Engineering and Technology Management 24 (3): 203-30.

Aldy, J. E. 2011. "Real-Time Economic Analysis and Policy Development During the BP Deepwater Horizon Oil Spill." Vanderbilt Law Review 64 (6): 1793-1817.

Baker, William E., and James M. Sinkula. 1999. "Learning Orientation, Market Orientation, and innovation: Integrating and Extending Models of Organizational Performance." Journal of Market-Focused Management 4 (4): 295-308.

Batista, Maria da Gracia, and Miguel Pina Cunha. 2009. "Improvisation in Tightly Controlled Work Environments: The Case of Medical Practice." FEUNL Working Paper Series 38 (Aug 2009).

Berkowitz, Aaron Lee. 2009. Cognition in Improvisation: The Art and Science of Spontaneous Musical Performance. Ph.D. 3365197, Harvard University. 
Brady, Malcolm. 2011. "Improvisation Versus Rigid Command and Control at Stalingrad." Journal of Management History 17 (1): 27-49.

Crossan, Mary. 2004. "Strategic Leadership and Organizational Learning." Academy of Management. The Academy of Management Review 29 (2): 222-40.

Crossan, Mary, Miguel Pina E. Cunha, Vera Dusya, and Joao Cunha. 2005. "Time and Organizational Improvisation." Academy of Management. The Academy of Management Review 30 (1): 129-45.

Crossan, Mary M. 1998. "Improvisation in Action." Organization Science 9 (5): 593-99.

Crossan, Mary M., and Marina Apaydin. 2010. “A Multi-Dimensional Framework of Organizational Innovation: A Systematic Review of the Literature." The Journal of Management Studies 47 (6): 1154-91.

Cunha, Miguel Pina E., Ken Kamoche, and Rita Campos e Cunha. 2003. "Organizational Improvisation and Leadership: A Field Study in Two Computer-Mediated Settings." International Studies of Management and Organization 33 (1): 34-57.

Cunha, Miguel Pina E., Rego Arménio, and Ken Kamoche. 2009. "Improvisation in Service Recovery." Managing Service Quality 19 (6): 657-69.

Cunha, Miguel Pina, Stewart R. Clegg, and Ken Kamoche. 2012. "Improvisation as “Real Time Foresight."” Futures 44 (3): 265-72.

Dennis, Noel, and Michael Macaulay. 2007. “'Miles Ahead"': Using Jazz to Investigate Improvisation and Market Orientation." European Journal of Marketing 41 (5/6): 608-23.

Edwards, David. 2008. Artscience-Creativity in The Post-Google Generation. Cambridge, MA: Harvard University Press.

Gibson, Will. 2006. "Material Culture and Embodied Action: Sociological Notes on the Examination of Musical Instruments in Jazz Improvisation." The Sociological Review 54 (1): 171-87.

Gilmore, Sarah, and Clive Gilson. 2007. "Finding Form: Elite Sports and the Business of Change." Journal of Organizational Change Management 20 (3): 409-28.

Halpern, Charna, Del Close, and Kim Johnson. 1994. Truth in Comedy: The Manual for Improvisation. Colorado Springs: Meriwether.

Hatch, Mary Jo. 1998. "Jazz as a Metaphor for Organizing in the 21st century." Organization Science 9 (5): 556-57.

Jaworski, Bernard J., and Ajay K. Kohli. 1993. "Market Orientation: Antecedents and Consequences." Journal of Marketing 57 (3): 53-70. 
Johnson, Peter M. 2015 An Empirical Study of The Relationship of Organizational Improvisation to Market Orientation. DPS Dissertation, Pace University NY

Kamoche, Ken, and Miguel Pina e Cunha. 2001. "Minimal Structures: From Jazz Improvisation to Product Innovation." Organization Studies 22 (5): 733-64.

Ketchen, David J., Jr., G. Tomas M. Hult, and Stanley F. Slater. 2007. "Toward Greater Understanding of Market Orientation and the ResourceBased View." Strategic Management Journal 28 (9): 961-64.

Kirca, Ahmet H., Satish Jayachandran, and William O. Bearden. 2005. "Market Orientation: A Meta-Analytic Review and Assessment of Its Antecedents and Impact on Performance." Journal of Marketing 69 (2): 24-41.

Kirsner, Scott (2015) "What big companies get wrong about innovation metrics." Harvard Business Review, May 2015

Kohli, Ajay K., and Bernard J. Jaworski. 1990. "Market Orientation: The Construct, Research Propositions, and Managerial Implications." Journal of Marketing 54 (2): 1-18.

Kumar, V., Eli Jones, Rajkumar Venkatesan, and Robert P. Leone. 2011. “Is Market Orientation a Source of Sustainable Competitive Advantage or Simply the Cost of Competing?" Journal of Marketing 75 (1): 16-30.

Moorman, Christine, and Anne S. Miner. 1998a. "The Convergence of Planning and Execution: Improvisation in New Product Development." Journal of Marketing 62 (3): 1-20.

Moorman, Christine, and Anne S. Miner. 1998b. "Organizational Improvisation and Organizational Memory." Academy of Management. The Academy of Management Review 23 (4): 698-723.

Narver, John C., and Stanley F. Slater. 1990. "The Effect of a Market Orientation on Business Profitability." Journal of Marketing 54 (4): 20$39 x$.

Randall, Mayumi Ogura. 1993. The History of Piano Improvisation in Western Concert Music. DMA diss., University of Cincinnati.

Senor, Dan, and Saul Singer. 2009. Startup Nation: The Story of Israel's Economic Miracle. New York: Hachette.

US Marine Corps. 1994. Warfighting Manual. Washington, DC: US Marine Corps.

Vera, Dusya, and Mary Crossan. 2004. "Strategic Leadership and Organizational Learning." Academy of Management. The Academy of Management Review 29 (2): 222-40.

Vera, Dusya, and Mary Crossan. 2005. "Improvisation and Innovative Performance in Teams." Organization Science 16 (3): 203-24. 
Weick, Karl E. 1988. "Enacted Sensemaking in Crisis Situations." The Journal of Management Studies 25 (4): 305-17.

Weick, Karl E. 1993. "The Collapse of Sensemaking in Organizations: The Mann Gulch Disaster." Administrative Science Quarterly 38 (4): 628-52.

Weick, Karl E. 1998. "Improvisation as a Mindset for Organizational Analysis.” Organization Science 9, no. 5: 543-55.

Weick, Karl E., Kathleen M. Sutcliffe, and David Obstfeld. 2005. "Organizing and the Process of Sensemaking." Organization Science 16 (4): 409-21.

\section{The Branding Imagination}

Martyn Straw (The Purposeworks, New York)

The value of brands is well known, not only in common marketing terms such as power drivers of share, preference, trust, loyalty, etc., but in dollar terms. They add billions of dollars to market caps because strong brands are annuities. They withstand storms such as bad product, press. They command premium prices.

The extent of their value is recorded in the Interbrand 2014 Best Global Brands report, which estimates the \#1 brand, Apple, to be worth $\$ 118,863 \mathrm{~m}, \mathrm{a}+21 \%$ increase over 2013. By comparison Samsung comes in at \#7 with an estimated value of $+15 \% \$ 45,462 \mathrm{~m}$, a little over a third that of Apple.

So what's wrong with Samsung? That $15 \%$ growth number suggests not a lot.

But it's not just Apple's numbers: Do Samsung customers form endless lines to get the new new thing?

It's also important to keep in mind these are brand dollar values, not physical sales. Something is happening to create incredible value around mystical magical, intangible assets worth billions of dollars.

Accordingly, as marketers we need direction on how to create magic! We cannot stumble around hoping for inspiration that is not relevant, or dull, unoriginal work that nobody cares about. We want a perfect blend of art and science: it's not enough to capture consumers' brains if you don't get their hearts.

The average consumer has access to all the knowledge in the world-how much the dealer actually paid for that car, what people think 
of cornflakes, what everyone is saying about their product and customer service experiences. Good behavior is not enough. Your customers must WANT YOU TO WIN!

\section{The Win/Win}

Here's the headline for all that follows: ensure that at all times consumers get their money's worth. We will go on to talk about the "win." It's not always a tangible offer, but one of the rules of magical branding is a head/heart proposition that emanates value.

As an example, consider supermarket owned brands, which have often been considered low cost commodities. But they have always been brands-friends of the consumer looking to save money. It was always clear whose side the brands were on. This aspect of the relationship was arguably more important than price alone. That friendship is now further cemented by significant product (and packaging) improvements that say even louder that the buyer is smart, and any stigma of penny saving has totally evaporated. It's not just about price. It's about win/win in a cycle of mutual loyalty.

There are different ways into the win/win brand relationship. Here are some:

\section{Immersion Branding}

This is not just about events and sponsorship, although they play a part. By definition we can look at any prospect as just not yet a consumer. The magic is to understand and communicate the brand experience.

Here is where on-line can play a key role in the arc of brand communications by adding a new dimension to the brand construct.

A good example is the "Pepsi Pass" world offering the third dimension of brand immersion with the Pepsi Pass, "coolest music, sports and live events," and not just deep discounts on the product (although these do exist). It is not just a beverage but also part of a rich, satisfying lifestyle that communicates the values of the brand.

Design = immersion: the very minimalist and clean lines of Apple products are an earned look and feel that passes along a sense of what using and feeling the devices is like. We don't need to be told how well they devices work together and apart-we just feel it.

Starbucks has taken this to the street. Globally, the brand is identically the "third place" between office and home, where customers can take out coffee or just go online. It has introduced Japan to the Venti.

Every Starbucks globally has the same set-up-although there are a few stores with no seats-penny wise, brand foolish. 


\section{Mirroring}

Fundamental to consumers' needs both practical and emotional. As discussed above the Branding Imagination captures the hearts and minds by demonstrating complete empathy and understanding of the consumer. Mirroring completely closes the gap between brand owner and brand buyer in a seamless dialogue. It may be the propensity of many brands to create a gap in communications in a brand monologue. This is the opportunity. The response to be sought is high scores for such measures as "brand for people like me."

This is not trickery. The challenge-and the gamble-is to build the proposition honestly on a caring and true insight. Things will turn horribly wrong if communications misjudge this.

And mirroring should operate all along the value chain, starting with the product: you cannot sell a bad one twice and any relationship between buyer and seller is cratered irreparably. Before you are brand owner you must walk in the shoes of your customer.

\section{Brand Provenance}

We can often play out in our minds where we imagine successful brands come from, invoking a sense of time and place. Despite current reality, in its brand world Coors comes to us from west of the Mississippi, Smirnoff from Russia, Jaguar from the bloodlines of the British racing tradition, Toyota Land Cruisers from the Serengeti, the privileged classes who inhabit the world of Ralph Lauren (but, interestingly, not Tommy Hilfiger). At the heart of the brand's story there should always be a sense of time and place that the consumer wants to be part of and believes is authentic.

Sometimes Brand Provenance is not a world but an overall idea or proposition. For instance, we might consider GE's long-standing "Imagination" idea a value we can all get behind. It's a salute to engineering integrity, innovation and grit, not just jet engines.

Once the Brand Provenance is fine-tuned and agreed, it must never be wandered from or become blurred-certainly never contradict itself by not behaving on-brand or consistent with brand values. Brand schizophrenia gets consumers confused and typically to lose trust.

\section{Brand Disobedience}

In every category there is a standard set of verbal and visual language that obeys a norm. Every bank, for instance, speaks broadly in the same voice of hospitality, friendliness, care, and the wonderful retirement life you can expect if you simply bank with them. Simply put, there is no 
differentiation in the category, and there seems to be no attempt to create win/win brands or to apply any of the principles discussed here that could create a stand-out bank brand.

We like brands that take a contrarian stance in their respective categories-brands that shake things up a bit-“zigging" to the category "zag."

An example is Subaru which-in a category that is obsessed with features and performance data-has simply aligned the brand with "love," and by extension, with memories, and a powerful way to express durability in the background.

There is a danger-anyone can go rogue, but it must be in a relevant way in honest pursuit of the win/win. The response goal from the target should be "how did they know that about me?" Not in a creepy way, but in the sense of a caring and listening brand.

\section{Advocacy Branding}

This is an evolution of the service brand. Service brands are typically not differentiating because they are all expected to serve-service is table stakes by definition. Service brands cannot be let down by the brand experience. Cable Companies, for example, need to take heed here. Everyone needs to step up into the next level we call Advocacy Branding.

The advocate brand transcends what the target wants to what the target will want. This is a dangerous play, but with high rewards. One old example of this is the ATM. No one could imagine such a thing, let alone demand one. More currently, Apple products are masters at bringing to market products and services we did not know we wanted. The iPad? Who knew?

Advocacy Branding is a component of marketing imagination. For too long brand owners have relied too much on spinning product sameness instead of insight, which invariably devolves to price wars. This is not win/win. Furthermore, since it is impossible to sell a poor product twice, shortsighted. Nevertheless we encourage the use of "advocacy positioning" to spotlight thoughtful benefits in an engaging, pleasing way that touches the heart and soul.

Advocacy Branding is hard work. It means digging deep into the heart and soul to understand their dream products and services. This is not necessarily a call for billion-dollar investments into NPD, but a wakeup call to the brand strategist who should know, at the very least, the unmet craving of the target.

This is a piece on creating brands, not just communications, although they are obviously interwoven. Accordingly, the best construct is to understand the most differentiating, relevant and future proof benefit of the offering, and to align it seamlessly with an integrated 
product/experience/communications brand whole, ideally being out ahead of consumers, surprising them with brand "gifts" they were not expecting. This is the win/win.

\section{$B 2 B$}

The challenge here is to not forget the win/win. That you are a good company and do what you do well in your space does not make you different-it just allows you to contend. For some reason there is an invisible line between consumer marketing and corporate marketing. It's a false distinction. Coming to the client's service with, say, a "Disobedience" or "Advocacy" proposition, for instance, is likely to put more of a spark into the view and competitive spirit of the brand. This is owed, not just to the customer, but to the employees.

\section{Will Algorithmic Playlist Curation Be the End of Music Stardom?}

Patrik Wikström (Queensland University of Technology, Australia)

It is 2015 and there are no indications that the relentless digital transformation of the music economy is about to slow down. Rather, the music economy continues to rapidly reinvent itself and industry powers, positions and practices that were redefined only a few years ago are being questioned once again. This paper examines the most recent changes of the music economy as it moves from a product-based towards an accessbased logic. This essay starts out by recognising the essential role of technology in the evolution of the music economy. It then moves on to a discussion about the rise of so-called access-based music business models and points out some of the controversies and debates that are associated with these models and online services. With this as a background the paper explores how access-based music services, and the algorithmically curated playlists developed by these services, transform the relationship between artists, music and fans and challenge the music industrial power relationships and established industry practices once again.

\section{The technology-driven music economy}

The business, as well as the musical evolution, of the music economy is heavily shaped by technological change. Recording technologies such as multi-track recording and non-linear editing; distribution technologies such as the music cassette and the Compact Disc; promotional media such as broadcast radio or video-sharing websites; performance technologies 
such as the electrical microphone, the amplifier, or the sequencer, and a whole range of other music technology innovations, have shaped the sounds, aesthetics, and music business models during the past century and continue to shape the economy into this century. Many of these innovations have been truly disruptive, in the sense that they have ruthlessly made existing practices and competences obsolete. Artists, composers, and businesses that relied on the superseded technology have been forced out of business, while new artists, sounds, genres and business practices, able to benefit from the new innovations, have taken their place.

During the past two decades, there has been ample opportunity to observe the processes of creative destruction in the music economy. More or less all aspects of the music industrial value chain have been affected, but primarily the technologies for music promotion and distribution have been at the centre stage of digital disruption. Accounts of this process usually take 1999 as its point of departure. 1999 was the year when the global recorded music industry had experienced two decades of continuous growth, largely driven by the rapid transition from analogue vinyl records to digital Compact Discs. The transition encouraged avid music listeners to purchase much of their music collections all over again in order to listen to their favourite music with "digital sound." As a consequence of this successful product innovation, recorded music unit sales more than doubled between the early 1980s and the end of the 1990s. It was with this backdrop that Napster, the first peer-to-peer filesharing service was developed and released to the mainstream music market.

Napster was an illegal file-sharing service and, together with a range of similar services that followed in its path, it reduced physical unit sales in the music industry to levels that had not been seen since the 1970s. The recorded music industry struggled during much of the 2000s with how to cope with the overwhelming online piracy. The legal and technical attempts to thwart these illegal practices eventually proved to be unsuccessful, and the impact on the music economy was transformative, irreversible and, for many music industry professionals, also devastating. Thousands of people lost their livelihood; large and small music companies folded, or were forced into mergers or acquisitions.

\section{The rise of access-based music services}

Slowly the realisation dawned that online piracy could not be stamped out and, in order for the industry to survive, new business models had to be developed that were able to compete with piracy. These business models had to offer music in a format that made it appear like it was free to the consumer, but somehow nevertheless were able to generate revenues for creators and rights holders. 
After a lengthy period of entrepreneurial business model experiments, the surviving model was a radical shift from established practices. It required the industry to abandon the fundamental music industrial logic, where music was packaged as products and sold at a strictly regulated unit price, in favour of a new model where music was sold as a service for a monthly fee.

These so-called access-based music services offer a music subscription service that does not charge their consumers for downloading individual songs or albums. Rather, for a monthly subscription fee, these services offer unlimited access to a large music library which the subscribers have access to, only as long as they pay a monthly fee. ${ }^{3}$ The market has quickly accepted access-based music services. The model has captured more than 80 per cent of a number of recorded music markets in Europe and Asia, and it is about to take over permanent downloads as the dominating business model in the global economy for recorded music.

\section{A controversial shift}

The transformation from a product-based to an access-based music economy has not been entirely uncontroversial. During the early days of access-based music services, there was wide-ranging scepticism in the music industry about the fundamental viability of the model. As time moved on however, and revenue-as well as the number of service providers on the market-continued to increase, these sceptics slowly but surely accepted the viability of the new business model. However, a number of questions related to these services remain unresolved. The most urgent one concerns the fairness and transparency of the repatriation of revenues generated by access-based music services from consumers, via aggregators and record labels, to composers and musicians. The access-based service providers report billions of dollars in royalty payouts to record labels and other rights holders, but at the same time, there is anecdotal evidence from musicians, artists and composers of seemingly very popular songs indicating that the revenues from these services are not appropriately shared with them. These are legitimate grievances that have to be resolved in order for record labels and other digital music aggregators to hold on to some level of legitimacy in the new music economy.

\section{The role of brands in the music economy}

While the question of fair and transparent repatriation of royalties from

${ }^{3}$ Some access-based services also offer an advertising-funded, free version of their service which allows users access to the music library, but with limited functionality. 
access-based music services is indeed a major concern, this essay focuses on a question that is not yet as heavily discussed, but which may have an even more radical impact on the functioning of the emergent music economy. A useful starting point for this discussion is the role of brands in the music economy.

Music brands in a product-based music industry logic are primarily associated with an artist (e.g. Taylor Swift) or a band (e.g. One Direction), who during a period of time builds significant value into the brands that are associated with their craft and practice. To be fair, there are other types of brands in the recorded music economy-for instance, compilation albums (e.g. Now That's What I Call Music) and record label imprints (e.g. Ministry of Sound)-but an overwhelming number of brands are nevertheless associated with an individual artist or band. Such music brands often serve as platforms for long, loyal and profitable relationships between fans and artists. The brands are also increasingly used to organise equally profitable relationships with other brands, via multimillion sponsorships and endorsements (for example, Taylor Swift endorsing Diet Coke, or One Direction endorsing Pepsi). The investment in, and development of, such brands are normally considered as a music company's most essential activity and the one that constitutes a considerable, if not the largest, part of the company's cost base.

Music is an experience good, meaning that it is difficult to estimate the value of a music product before it has been listened to. In a productbased music economy, a recognisable music brand is one of a number of mechanisms (expert and user reviews are other such mechanisms) that assist consumers in their purchasing decisions, and reduce the risk of the latter's spending their limited music budgets on music that does not match their musical preferences.

While music brands are necessary filtering mechanisms for consumers in a product-based music economy, consumers in an accessbased music economy make their music listening decisions in a very different way. Rather than carefully selecting a number of products to add to a limited but slowly expanding music collection, consumers pay a monthly fee to get access to a very large music library. As the market for access-based music services continues to evolve, competing services strive to expand their libraries to include an increasing number of songs and ultimately to make them as comprehensive as possible. Today, there are still minute differences between the libraries offered by competing access-based music services, but looking into a not too distant future it is clear that the service providers' libraries will become increasingly comprehensive and increasingly indistinguishable. The services will no longer be able to use their music libraries as a point of differentiation. 


\section{Algorithmically curated musical experiences}

To some extent the market has already reached this state, as service providers more or less have ceased promoting the size of their libraries. The point of differentiation has rather moved on to the services' "contextual features" that assist users in navigating the enormous music libraries and making decisions about what song to listen to next. The access-based music service providers' development of such contextual features is still in its infancy, and at this stage, a seemingly trivial, but still fundamental, structure in this differentiation strategy is the curated playlist. A basic playlists consist of a set of songs curated by either a human or an algorithm, focused on a specific theme, mood, or activity. Some playlists may be fairly static and consist of songs appropriate for a dinner party or for focused studying. Other more dynamic playlists are algorithmically curated, based on an analysis of data from sensors in users' mobile devices, the users' previous music listening behaviour, their relationships with other humans via social media, and acoustic characteristics of the millions of songs available in the service's music library. This analysis make it possible to curate a personalised musical experience that gives the user the "right music for every moment," to quote the leading access-based music service Spotify. Most access-based music services invest heavily in playlist curation capabilities, and there is high demand for music data analytics expertise, which also is reflected in an intense acquisition frenzy led by service providers with available capital. For instance, Spotify acquired the music data analytics company, The Echo Nest, in 2014; the internet radio provider Pandora acquired another music data analytics company called Next Big Sound in 2015; and a few months later the world's largest company, Apple, acquired the UKbased music data analytics company MusicMetric.

It is vital to realise that this kind of algorithmic playlist curation reduces the music listener's cognitive load by essentially removing the need to develop relationships with the creators of the songs that match their musical preferences. The algorithms efficiently supplant the function of the artist-based brands that were necessary components in the now fading product-based music economy. In the access-based music economy, there is no need for consumers to remember or recognise artist-based brands in order to get a satisfying musical experience. The only relationship the music listeners need to manage is the one with their access-based music service provider.

If we follow this reasoning to its logical conclusion, it leads to a condition where artists are no longer a cultural phenomenon, with loyal fans and strong brand recognition. Rather, they are anonymous producers of sound components that are ready to be combined by automatic algorithms into a comprehensive musical experience personalised to individual users' preference, mood or activity. This change constitutes a significant redistribution of power, from the artists and the music 
companies that previously controlled the relationship with the music listeners, to the access-based music service providers and the algorithmic curators of ever-evolving individualised playlists.

\section{Consequences for established music industrial structures}

While it is unlikely that the hypothetical condition laid out above will ever be completely attained, it is nevertheless very likely that a gradual shift towards an access-based music economy significantly reduces the value and significance of artist-based music brands. As the brands' roles as repositories of economic value and signposts for consumers' music listening decisions diminish, the role and purpose of the music company, and primarily the record label, need to be redefined once again.

The music industry is traditionally structured into three major sectors. Two of these sectors are consumer-oriented, and focus on live music and recorded music respectively. The third sector is focused on the licensing of musical rights for various purposes: for instance, for use of a song as a component in an audio-visual production for film or television; or for playing music in a public venue. Organisations in the recorded music sector have already been forced to radically redefine their roles during the ongoing digital transformation of the music economy. Digital technologies for music recording, as well as for music distribution, have led many organisations in this sector to abandon their operations for physical music distribution, as well as their facilities for high-quality studio recording. The value-creating activities that up until this point have sustained and even increased its significance are the record labels' marketing and brand building activities. The reason behind the heightened significance of marketing in the recorded music economy is relatively well established: digital technologies have lowered the entry barriers to the recorded music industry-a fact which has dramatically increased the number of titles released onto the market, and increased the marketing resources required to break through the noise.

\section{Conclusions}

The ongoing move from a product-based to an access-based music economy, where algorithms take over the role of music brands and marketing professionals alike, will potentially lead to a radical shift of power from the production and recording of music to the curation of musical experiences. Such a shift would constitute a fundamental challenge to the recorded music company's final bastion. It remains to be seen how far-reaching this impact eventually will be, but one possible future scenario is that the recorded music industry sector in practical terms will cease to exist and be folded into the music licensing industry sector. Such a change would be a natural extension of an already ongoing process, where a plethora of new media outlets have multiplied the 
revenues from music licensing and moved the music licensing sector closer to the music industrial epicentre. The one thing that is certain is that technological development will continue to shape the evolution of the music economy, and that the music industry of the future will be very different than the music industry of today.

\section{Exploring Creativity in Crowdsourcing}

Jie Ren (Fordham University, New York)

Where can we get good ideas with low cost? Recent researchers (e.g., Brabham 2008; Cardoso and Ramos 2009; Chanal and Caron-Fasan 2008; Kleemann and Günter 2008; Leimeister et al. 2009; Ramos et al. 2009; Schenk and de Strasbourg 2009) probably would suggest "the crowd." Indeed, crowdsourcing (derived from the Chinese proverb: "two heads are better than one" [Yu and Nickerson 2011]) has increasingly been the easiest and most inexpensive method to gain creative/innovative ideas. With the current or potential shortage of R\&D resources, firms are encouraged to rely on the collective and distributed intelligence disseminated in the crowd for future competitiveness. Numerous innovation requesters have either hired a third-party information system vendor and/or designed their own websites to connect with the crowd in order to earn un(der)paid ideas (Kleemann and Günter Voß 2008). However, are the ideas snatched from the crowd radically innovative and entrepreneurial enough that they can bring surplus values to firms and/or markets?

In order to answer this question, this paper blends the literatures of entrepreneurship and innovation management to explain crowdsourcing (e.g., Oswick et al. 2011). First, entrepreneurship literature suggests that the crowd does not have the motivation of an entrepreneur (the consistent pursuit of profit) (Schumpeter 1961a). Therefore, the crowd is not "alert" (Kirzner 1997) enough to create radical ideas and to make substantial opportunities. Second, innovation management literature suggests that creativity needs prior domain knowledge (for example, market expertise) (Shane 2000). In many cases, domain knowledge is something largely missing from the crowd. Hence, ideas from the crowd may neither be motivated, nor have sufficient domain knowledge, to create radical ideas. 


\section{Crowdsourcing}

Crowdsourcing, first used by Howe (2006), is the act of outsourcing tasks traditionally performed by an employee or contractor, to an undefined, large group of people or community (that is, a crowd), through an "open call." Individuals in the crowd, in most cases, are slightly rewarded (e.g. Mechanical Turk) or unpaid (e.g. CitizenScience). Many innovation requesters-individuals or organizations-are using the crowd online for creative ideas or even for real innovations (like formally written programming scripts).

With the advantages of low cost and easy access, crowdsourcing has quickly spread worldwide. Due to the large capacity of the crowd, innovation requesters (firms or individuals) have been utilizing the crowd's wisdom via online platforms. For example, Mechanical Turk, 99designs, and CrowdSpring are online platforms designed by a third party for requesters to outsource tasks to the crowd. Alternatively, companies including Half Bakery, Threadless, MicroSoft (ImagineCup), and Dell (IdeaStorm) have conducted crowdsourcing campaigns through their own websites. In China, thousands of innovation requesters have been posting their requests for creative ideas from the crowdsourcing website: Task.cn. It is so popular that a new word 威客 (weike) has even been created: to refer specifically to those who take on tasks from crowdsourcing websites.

Furthermore, the encouragement from academia with regard to crowdsourcing has accelerated the practice's pervasion in the practitioners' arena. For example, Chanal and Caron-Fasan (2008) suggest that, due to the common lack of resources for innovation in small and medium sized enterprises (SMEs), a service capable of involving the crowd in large networks (filled with useful and reachable knowledge) is crucial to the future competitiveness of crowdsourcing.

Specifically, many researchers have started to draw attention to the motivations of crowd members. For example, Hars and Ou (2002) have examined the motivations of programmers contributing their effort to an open call for open-source software. Their motivations can be identified as forming two general categories: internal (for instance, intrinsic motivation, to have fun, and so on) and external (direct or indirect monetary compensation, and recognition by others, and so forth). Others (Xu et al. 2009) have empirically supported the idea that the reputation gained, and skills learned, from open-source software project participation may help programmers with future work opportunities. In addition, in two case studies, Ren (2011a) has identified four stages of crowdsourcing: identifying, requesting, evaluating, and retaining the crowd. She also confirmed the motivations just mentioned and eliminated possible new motivations of the crowd. That is, the crowd in her case studies is neither interested in monetary rewards, nor cares about intellectual property rights for ideas it has submitted to innovation 
requesters.

In summary, the rationale behind the pervading phenomenon of crowdsourcing can be explained as "two heads are better than one." The more ideas that are submitted from the crowd, the more creativity is expected from the submitted ideas. However, the question remains: in order to add new values and disrupt the current market layout, can these ideas be radical and entrepreneurial enough?

\section{Entrepreneurship literature}

Entrepreneurship literature can answer this question, since ideas generated by entrepreneurs are actually radical. As the pioneers who economically advance the society (Schumpeter 1961a), entrepreneurs create unique ideas. These ideas can be a novel combination of five possible innovations (that is to say, a new good, a new market, a new method, a new source of supply, and a new organization) (Schumpeter 1961a). The combination is so radical that it can trigger market resistance in the short term and then bring new values to new ventures (and their markets) in the long term.

Even for the minds of the ever-motivated entrepreneurs, radical ideas are difficult to create and need concentrated alertness (Kirzner 1957). They pursue entrepreneurial profit. "Entrepreneurial profit... a (significant) surplus over costs" (Schumpeter 1961a: pp.128), drives entrepreneurs to create values destructive of the existing economic equilibrium (Schumpeter 1961b): "new businesses are continually arising under the impulse of the alluring profit" (pp.131). The new value, to be destructive, cannot be incrementally new. It has to be radical: at least, radical enough to earn entrepreneurial (significant surplus) profit. "Without (creative) development (upsetting the norm) there is no (significant surplus) profit, without profit no development" (Schumpeter 1961a, pp.154). Simply put, the motivation of pursuing entrepreneurial profit is elementary and crucial to creating radical ideas.

However, the crowd, in sharp contrast to entrepreneurs, rarely desires monetary rewards. Mostly, those concerned want to either show their values in helping others, or kill time via online activities, or continue their hobbies, and so on. For example, a participant in the crowdsourcing setting once told Ren (2011a) during their interview: "I still want to do it (participating in the crowdsourcing project) without any monetary reward." Even if the crowd were to desire to get rich, crowdsourcing is definitely not a good way to go about it-the reason being that crowdsourcing websites always underpay the crowd or exploit their intelligence for free. Revised from Schumpeter's phrase, the above arguments can be summarized as: without the motivation of earning entrepreneurial profit, radical ideas can rarely be expected from the crowd. 
In the setting of crowdsourcing, some ideas involve the implementation of existing technical invention, such as advertising electronic cars. Prior knowledge, for example related to electronic cars, whether developed from work experience, education or other means, will influence people's abilities (Roberts 1991) to comprehend, interpret and exploit opportunities in a way lacking that prior knowledge cannot replicate. In short, if a person doesn't understand the structure and strength of electronic cars, how can s/he possibly come up with a radical slogan, and accordingly change potential buyers' perception of electronic cars?

The crowd mostly consists of individuals who don't have domainrelated expertise. Therefore, they cannot discover entrepreneurial opportunities and create radical ideas. Even for open source software communities (the crowd with a certain level of expertise), their voluntary collaboration can probably advance the software incrementally, but not radically, since they don't have the motivation to pursue entrepreneurial profit.

Therefore, in order to earn significantly beyond average profit, entrepreneurs by definition need to generate new ideas/innovations themselves and accordingly create opportunities destructive of the existing economic equilibrium (Schumpeter 1961b). Any lack of prior knowledge would let these money-earning opportunities slip away. "Each person's idiosyncratic prior knowledge creates a knowledge corridor that allows him/her" (Shane 2000, pp. 452), not others, to discover entrepreneurial opportunities. Therefore, the crowd may not be programmed to create radical and entrepreneurial ideas.

\section{Innovation management literature}

Innovation management literature can also help explain the original question, in that it suggests that radically innovative ideas (as opposed to incrementally innovative ideas) require significant resources, capabilities and knowledge, and consequently incur high uncertainty and disagreement. However, crowd members in general don't acquire those resources, capabilities or knowledge. Therefore, their ideas tend not to be radical.

As in entrepreneurship literature, radical ideas need domainrelevant skills. Similarly, innovation management literature suggests that these skills are one of the three components leading to creativity (Amabile 1983, 1996), and that these skills represent "the ability to learn and apply certain types of domain-specific knowledge" (Taggar 2002, p.316). In order to gain these skills, an individual can accumulate familiarity with the domain in question through "memory of factual knowledge, or technical proficiency" (Taggar 2002, p.316). Diverse as the crowd can be, it's hard to locate a few individuals in it who have acquired 
domain-relevant skills. Complementary to the entrepreneurship literature's argument that lack of knowledge impedes the crowd from creating ideas based on existing technical inventions, innovation management literature suggests more. That is, prior knowledge can not only inspire new thinking about existing technical invention, but it is also the pathway to new inventions, and further to radical innovations. Imagine: if Mark Zuckerberg (the founder of Facebook) hadn't acquired superior programming skills and understood the mechanisms of other networking tools (e.g. MSN), he wouldn't have created Facebook (which was an extremely radical/creative idea that revolutionized people's living styles). In contrast, although there are a few crowds (for instance, communities of open source software enthusiasts) with prior knowledge of their domain of interest, the general crowd does not possess this attribute. Therefore, normally, the general crowd (unlike knowledgeable individuals) can only advance the existing innovation incrementally (for example, by combining two existing technologies or products). Therefore, without prior domain knowledge, creative innovations or radical relevant ideas can rarely be created from the crowd.

\section{Blending the two literatures}

By blending the two literatures (e.g., Oswick et al. 2011), this paper aims to explain why ideas created from the crowd may not be radical/creative enough to create a substantial surplus profit. Entrepreneurship literature indicates that in order to create radical ideas, the idea providers need to have prior knowledge (Shane 2000) to acquire keen insight into the idea domain and also to be motivated for entrepreneurial profit (Schumpeter 1961a), so that entrepreneurs can be alert to the creation of radical ideas. Moreover, innovation management literature echoes the importance of domain-relevant skills (Amabile 1983, 1996) for generating radical ideas (Rogers, 2000). In sum, the two literatures suggest that radical ideas can be generated only if idea generators, firstly, are motivated for entrepreneurial profit and, secondly, have domain knowledge.

\section{Comparison: idea creativity from entrepreneurs versus that from the crowd}

According to the monetary desires and expertise levels as discussed, idea providers can be categorized as, firstly, entrepreneurs; secondly, highexpertise crowds (very few in number); and, thirdly, low-expertise crowds (see Figure 1). Entrepreneurs, who consistently pursue entrepreneurial profit (Schumpeter 1961a) and are usually experts (Shane 2000) in some domains, are motivated and able to create radical ideas. Since the number of entrepreneurs is usually small compared to the crowd size, radical ideas are unlikely to be many. Open source software communities, which can be labeled high-expertise crowds, on the other 
hand, are able to provide radical ideas. Nevertheless, aiming to develop and continue their hobbies (e.g., Ren 2011a) and to get involved in related online activities, these software developers are generally not motivated enough to stay alert and to create radical ideas. Instead, the ideas they make public tend to advance the existing software and are for the most part incrementally innovative, rather than radical.

In contrast, due to the lack of prior knowledge and desire for entrepreneurial profit, the low-expertise crowd is rarely able to provide radical ideas. Nonetheless, for some low information asymmetry products (Brush and Artz 1999; Nelson 1970), such as chairs, desks, and lamps, the crowd can gain relevant knowledge through daily consumption. In such cases, it is possible for members to provide incrementally innovative ideas based on their increasing demands of these products (Ren 2011b). However, like software enthusiasts, the low-expertise crowd (for instance, "turkers," or participants from Mechanical Turk) is not motivated to stay alert and create radical ideas.

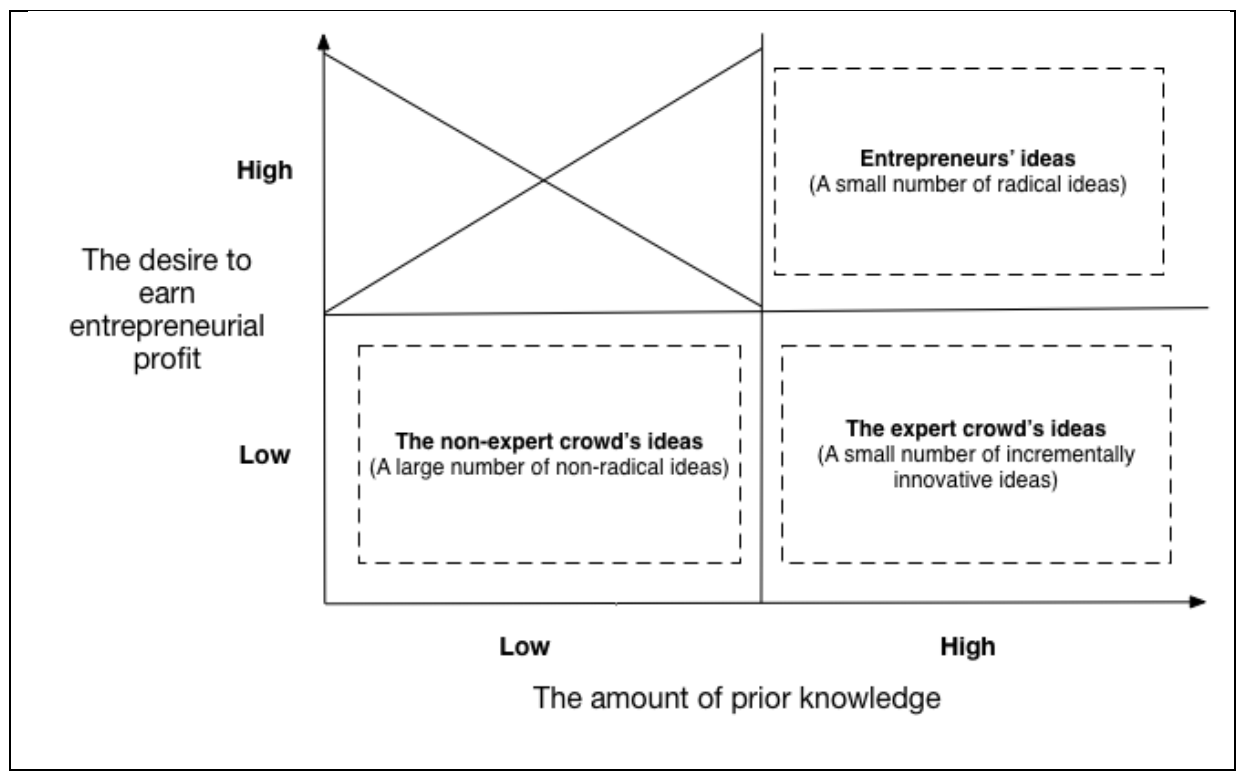

Figure 1: Comparison of idea creativity from entrepreneurs versus that from the crowd

\section{Conclusion}

This paper doesn't deny the obvious benefits of crowdsourcing. Instead, it suggests that researchers and practitioners, who use the crowd for innovative outputs, should leverage the crowd more strategically. First, due to the shortage of $R \& D$ resources, SMEs can acquire inspiration from the crowd's distributed and collective intelligence for incrementally improving their current products and services. Because of the large capacity in the crowd, a huge number of ideas can be expected from the crowd. For example, through the crowdsourcing web portal, "My 
Starbucks Ideas," Starbucks has been using its current and potential customers to gain thousands of ideas for improving its existing products and services.

Although the black box of how entrepreneurs create radical ideas hasn't been illuminated, innovation requesters, especially researchers, can design human/computer interactive systems that would leverage inexpensive and collective human intelligence for radical ideas. However, the algorithms of such systems must leverage the diverse backgrounds of crowd members. For example, with specified instructions to combine, change and/or criticize existing ideas, crowd members can be trained to acquire some domain knowledge (Ren et al. 2014). Then the capacity of the crowd may be increased for more creative ideas. As long as innovation requesters are motivated for entrepreneurial profit, they may stay alert and select radical ideas from this large pool of ideas submitted from the crowd.

\section{References}

Amabile, T. M. 1983. "The social psychology of creativity: A componential conceptualization." Journal of Personality and Social Psychology, 45: 357376.

Amabile, T. M. 1996. Creativity in Context. Boulder, CO: Westview Press.

Brabham, D. 2008. "Crowdsourcing as a model for problem solving: An introduction and cases," The International Journal of Research into New Media Technologies, 14(1): 75-90

Brush, T. H. and Artz, K. W. 1999. "Toward a contingent resource-based theory: The impact of information asymmetry on the value of capabilities in veterinary medicine." Strategic Management Journal, (20)3: 223-250.

Cardoso, M. and Ramos, I. 2009. Open Innovation and the Solver Community, ACM

Chanal, V. and Caron-Fasan, M. 2008. "How to invent a new business model based on crowdsourcing: the Crowdspirit $₫$ case." Paper presented at Conférence de l'Association Internationale de Management Stratégique, Sophia-Antipolis

Hars, A. and Ou, S. 2002. "Working for free? Motivations for participating in Open-Source projects." International Journal of Electronic Commerce, 6(3): 25-39.

Howe, J. 2006. "The rise of crowdsourcing." Wired Magazine, 14: 1-5

Kirzner, I.M. 1997. "Entrepreneurial discovery and the competitive market process: An Austrian approach." Journal of Economic Literature. 35 (March): 60-85.

Kittur, A. Chi, E. and Suh, B.. 2008. "Crowdsourcing user studies with 
Mechanical Turk." Proceeding of the SIGCHI Conference on Human Factors in Computing Systems, 4/5: 453-456.

Kleemann, F. and Günter Voß, G, 2008. "Un(der)paid innovators: The commercial utilization of consumer work through crowdsourcing." Science, Technology \& Innovation Studies, 4(1): 5-26.

Leimeister, J., Huber, M., Bretschneider, U. and Krcmar, H. 2009.

"Leveraging crowdsourcing: Activation-supporting components for ITbased ideas competition." Journal of Management Information Systems, 26(1): 197-224.

Nelson, P. 1970. "Information and consumer behavior." Journal of Political Economy, 78(2): 311-329.

Oswick, C., Fleming, P. and Hanlon, G. 2011. "From borrowing to blending: Rethinking the processes of organizational theory bilding." Academy of Management Review, 36(2): 318-33.

Ramos, I., Cardoso, M., Carvalho, J. and Graça, J. 2009. "An action research on open knowledge and technology transfer." IFIP International Federation for Information Processing, 301: 211-223.

Ren, J. 2011, "Who is more creative, experts or the crowd?." The proceeding of the 17th Americas Conference on Information Systems, 1: 771-783.

Ren, J. 2011. "Exploring the process of web-based crowdsourcing innovation." Proceedings of the 17th Americas Conference on Information Systems. 3: 1804-1818.

Ren, J., Nickerson, J. V., Mason, W., Sakamoto, Y. and Graber, B. 2014. "Increasing the crowd's capacity to create: How alternative generation affects the diversity, relevance and effectiveness of generated ads." Decision Support Systems, 65: 28-39.

Roberts, E. 1991. Entrepreneurs in High Technology: Lessons from MIT and Beyond. Oxford University Press, New York.

Rogers, E. M., 2000. Diffusion of Innovations. (5th Edition.) New York: Free Press.

Schenk, E. and de Strasbourg, I. 2009. "Crowdsourcing: What can be outsourced to the crowd, and Why?' Workshop on Open Source Innovation, Strasbourg, France.

Schumpeter, J. A. 1961a. "Theory of economic development: An inquiry into profits, capital, credit, interest, and business cycle." In S. Shane (ed.), The Foundations of Entrepreneurship, Volume 1, pp. 120-178. Cheltenham: Edward Elgar Publishing.

Schumpeter, J. A. 1961b. "The process of creative destruction, in Capitalism, Socialism and Democracy." In Scott Shane (ed.), The Foundations of Entrepreneurship, Volume 1, pp. 178-184. Cheltenham: 
Edward Elgar Publishing.

Shane, S., 2000. "Prior knowledge and the discovery of entrepreneurial opportunities." Organization Science, 11(4): 448-469.

Taggar, S., 2002. "Individual creativity and group ability to utilize individual creative resources: A multilevel model." Academy of Management Journal, 45(2): 315-330.

Xu, B., Jones, D. and Shao, B. 2009. "Volunteers' involvement in online community based software development." Information \& Management, 46: 151-158.

Yu, L., and Nickerson, J. V. 2011. "Cooks or cobblers?: crowd creativity through combination." Proceedings of the SIGCHI Conference on Human Factors in Computing Systems, 1393-1402.

\section{Anthropology: Moving Beyond Companies' “Creative” and "Innovative" Toolkit}

Filip Lau and Mikkel Brok-Kristensen (ReD Associates, Copenhagen, Denmark)

2014 was a big year in sports. The two biggest events with a global audience were probably the Winter Olympics in Russian Sochi and the Soccer World Cup in Brazil. Preparing for such events starts years in advance for an athletic gear company. In one of these companies, management decided to use 2014 as a platform to launch a whole new generation of "creative" and "innovative" offerings to capitalize on the increased worldwide attention. Having such a focus on your product category is simply an opportunity that cannot be missed. In early 2012, this particular company started to brief designers and marketers on how to make 2014 a record year. Their mission was to show the world the best the company could offer and to discover new dimensions of what an athletic gear company could provide sports fans.

During this time period, management produced a flurry of socalled "product briefs" that were distributed throughout the company. These 2-page long briefs described the problem to be solved, the likely solution, the intended target audience, and so on. There were briefs on team jerseys, on football shoes, on gym shoes, on footballs and more.

Let's take a look at a typical example-a brief for a gym shoe. It reads like this: "The shoe should exhibit the idea of breathability in the Upper combined with Midfoot support during dynamic strength 
movements." The brief goes on with similar industry-specific language about feet, cushioning, laces, and heels. What does this tell us? For us, it shows that the company in question is first and foremost a shoemaker at heart. So, even when it challenges itself and intends to build innovative offerings, it begins with a technical brief for a shoe. The brief illustrates to all of us not working in the shoemaking industry that the people in that business operate with a pretty narrow definition of where it is allowed to be creative and innovative.

The gym shoe brief is a telling example of how companies think when they intend to build something new and revolutionary: from the very first step-the product brief-designers and developers are asked to create something that is close to the core of what the company already does, that is built on past experiences and existing capabilities. Which is all fine-if what you want is a state-of-the-art shoe. But what is innovative and creative about that? Hard to tell.

The company in question knows what it does. It is one of the biggest and most successful companies within sports equipment and athletic gear. What strikes us as odd is that when it decided to make 2014 a year of innovation and creativity, management started out by looking inside its organization, returning to the company's roots in shoemaking to find new solutions (admittedly combined with a strong and decades-old collaboration with the world's top professional athletes for specialized product development). It did not look to the softer social sciences or humanities for a new take on what "creative" and "innovative" could look like in the eyes of the users and consumers of the world (beyond product testing on focus groups). The gym shoe was a fairly representative example of how the company in question developed a suite of new products to be launched in 2014 .

But this is not the whole story. The sports company actually did something that would make a sociologist or ethnographer smile. A team of anthropologists was hired in preparation for the 2014 soccer World Cup. They were asked to help the company form a clearer perspective on the future of football and its role as a nation-building tool. The team asked the following questions. What role does soccer have in the lives of younger generations for the participating nations, especially the ones that were rising on the world stage at the time, like Russia and Mexico? What does it mean to be a young, aspiring Mexican, and how could the national soccer team be part of the nation-building of an edgy, up-and-coming country? Such questions are gefundenes fressen for ethnographers, sociologists, anthropologists and the like. The intention with such a study was to inform, direct and inspire designers and product developers in the sporting goods company.

Hiring the group of social scientists was seen as innovative and creative inside the company. And here we arrive at the main point of this opinion piece. Seen from the chair of many executives whom we meet in 
our daily work as external consultants, the social sciences and humanities bring something new to the table-an alternative approach to problemsolving, a school of thought that can provide perspective and direction to questions about where the world is going that management science and business science cannot to the same degree. Bringing in anthropology as a problem-solving tool is seen as creative and innovative in its own right (Squires and Byrne, 2002). That's good-the door has been opened to the big companies-but is it good enough? Every day it becomes clearer and clearer to us that, as social scientists, we are only at the beginning of a journey (Campaign for Social Science, 2015). There's still some way to go before we are as established as trusted advisors to executives in the same way that engineers are. Right now most softer social scientists are positioned in executives' minds within the "creative and innovative" box (Moeran, 2013). While we as social scientists can pride ourselves on standing on the shoulders of 150 years of theory and methodology development, many are still seen as "new" and "different" by the management of companies out there. The number of executives seeking advice from social scientists is dwarfed by the number of, say, engineers or legal experts who shape the perspective of executives on a daily basis.

While engineering or medicine is broadly accepted as "applied natural science," there is still some way to go before anthropology or ethnography gets the same recognition.

The industry we want to be part of building is still very much under development. It lacks many of the symbols and institutions that constitute an industry in its own right, such as broadly recognized academic journals and conferences, awards, educational programs, associations and unions, and so on (Jordan, 2010).

In its effort to be taken seriously by executives as a true, standalone alternative to management- and business science, our industry must build more opinion pieces such as Madsbjerg's and Rasmussen's The Moment of Clarity (2014) if it is not to end up married to design thinking and other up-and-coming disciplines that borrow elements from the social sciences.

The big question is how to position the discipline of anthropology and other soft social sciences in the minds of executives. How can the discipline become indispensable to them in their decision-making on their bigger problems? How do we make our insights, recommendations and advice sound in the eyes (and ears) of executives?

\section{Key "innovative" and "creative" tools from the heart of the social sciences}

At the company we work in, we have spent the past ten years experimenting with getting the ears and attention of executives. We have found that the most interesting and juicy problems are found on C- or SVP-level in many of the organizations we work in, so that's where we 
want to work. And that is, frankly speaking, the level in a client organization where many social scientists have something truly valuable to offer. Problems needing abductive reasoning, problems with many types of potential outcomes - that's where social sciences can offer answers where management and business science have a harder time providing direction and clarity. Once we realized this, we have been on a journey to get into real conversations with the executives in the companies we work for.

Here, the challenges that arise speak to the core strategy of the business. These challenges center on what business a company is in-which has implications for the customers they are trying to reach, with what products, and through what channels and methods. What anthropology offers, a deep understanding of the customers, has little impact unless it's placed at the core the business (Skarzynski and Gibson, 2013).

At $\mathrm{ReD}$ we realized that, in order to have the impact we wanted, we needed to stop seeing ourselves as researchers and social scientists and more like management consultants utilizing the engine of social sciences. With this realization also came a formalization of something we'd always intuitively done as a part of every project: understand our clients and their industries, in the same depth as we did their customers.

It's now a set part of our problem-solving tool, where this is one of the so-called five lenses we use to explore and understand our clients and their issues. How are key employees working with running shoes in a sporting goods company actually thinking about the world of running? What kind of ideas and assumptions do they have about the people they serve? How is their world-view shaped by the fundamental beliefs of the company?

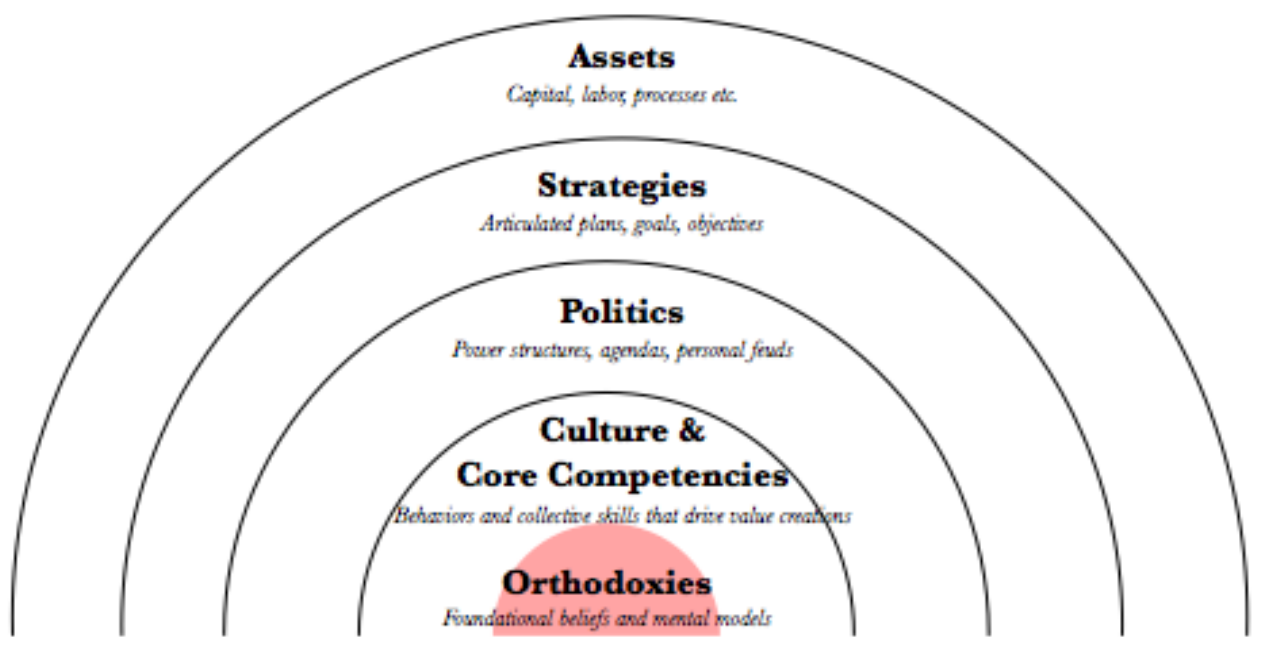

Figure 2: Overview of the five "lenses." (From internal ReD Associates training material] 
When attempting to understand how companies think about the world in general-and a specific phenomenon in particular-it has proven indispensable for us to understand the fundamental beliefs, mental models and orthodoxies that drive the behavior, policies, strategy development and decision-making processes in the company we serve (Bansi and Walters, 2011). Without this insight we cannot provide enough guidance to our clients, and we cannot tell what is old news or new news, what will likely work and what will not, and so on (see Figure 2). And we won't be able to speak their language-business, it's called-if we do not know how they see the world and internalize the key phrases and industry terms they use.

We look for many things in the data we collect. A key concept is the mapping of asymmetries between the client's orthodoxies and how the world (for instance, of running) is lived and perceived from other perspectives, for instance by users.

Here, utilizing the social sciences as a method provides a unique way of doing this. Instead of staying within the language used to frame the problem within the company, we translate what companies talk about into real-world phenomena. In the case of a sporting goods company a business problem might be how to sell more running shoes. Our job is to translate this into clear human experience, behind the problem that we can try to understand-why do people run? This seemingly simple trick-not studying running shoes, but studying running in its own right-is at the core of our practice and one of the most delicate analytical, yet highly creative, elements in any project we do. And this very flip also makes it possible for our clients, to take a step back and look at what's happening within their own business. By reframing the problem, we're also removing discussions of blame, of internal politics, of past discussions, and allowing everyone to look at their problems in a new light; boosting the creative and innovative thinking of the company as a whole, simply by providing a new perspective on their business.

\section{Conclusion}

"Innovation" and "creativity" are context-dependent terms. As external consultants, we have learned that, in many companies, bringing in sociologists and anthropologists for advice is seen as an innovative and creative act in its own right.

For social scientists, to move from a position as alternative advisor to become as central and trusted as, say, the engineer, it is necessary to focus on the challenges at the C-and SVP-levels in companies.

These challenges center on what business a company is in-which has implications for what customers they are trying to reach, with what products, and through what channels and methods. 
What anthropology offers, a deep understanding of the customers, has little impact unless it's placed at the core the business.

\section{References}

Campaign for Social Science 2015. The Business of People: The Significance of Social Science over the Next Decade. London: SAGE Publications.

Jordan, Ann T. 2009. NAPA Bulletin, Practicing Anthropology in Corporate America: Consulting On Organizational Culture. Hoboken, NJ: John Wiley \& Sons.

Jordan, Ann T. 2010. "The importance of business anthropology: Its unique contributions." International Journal of Business Anthropology 1

(1): 15-25.

Madsbjerg, Christian and Mikkel B. Rasmussen 2014. The Moment of Clarity. Boston: Harvard Business Review Press

Moeran, Brian 2013. The Business of Creativity: Toward an Anthropology of Worth. Walnut Creek, CA: Left Coast Press..

Nagji, Bansi and Helen Walters 2011. "Flipping Orthodoxies: Overcoming Insidious Obstacles to Innovation: Case Study." Boston: Harvard Business Review Press.

Skarzynski, Peter, and Rowan Gibson 2013. Innovation to the Core: A Blueprint for Transforming the Way your Company Innovates. Cambridge, MA: Harvard Business Press.

Squires, Susan, and Bryan Byrne, eds. 2002. Creating Breakthrough Ideas: The Collaboration of Anthropologists and Designers in the Product Development Industry. Westport, CT: Praeger Pub Text. 